\title{
La mala administración de la seguridad pública'
}

\section{The Maladministration of Public Security}

\author{
John GLEDHILL \\ The University of Manchester (Reino Unido) \\ john.gledhill@manchester.ac.uk
}

Recibido: 6 de diciembre de 2012

Aceptado: 28 de mayo de 2013

\begin{abstract}
Resumen
Este artículo examina políticas públicas basadas en la idea de que las situaciones en áreas de marginación social amenazan la seguridad de todos los otros residentes urbanos. Utilizando evidencias de Río de Janeiro, San Pablo y Salvador, las tres mayores ciudades de Brasil, donde el planteamiento de la mano dura goza con frecuencia de apoyo popular y donde la significativa reducción de la pobreza y la desigualdad social no han reducido el crimen y la violencia, el análisis demuestra las contraproducentes consecuencias de simples políticas de represión, especialmente en el contexto del modelo de desarrollo urbano neoliberal basado en la "acumulación por desposesión" y en la privatización del poder público que actúa en contra del éxito de la reforma policial. El artículo explora los modos en que, a pesar de nuevos compromisos para lograr justicia social, el estado sigue siendo parte del problema junto con las implicaciones de las diferencias en la organización de tráfico de drogas y las formas alternativas de "pacificación" que ofrece "la ley del crimen". Criticando una política securitaria que prioriza una guerra teatral contra la delincuencia que criminaliza la pobreza y la adicción a las drogas, el texto defiende la democratización de la producción de políticas públicas de seguridad, que entienda qué tipo de seguridad prioriza la gente pobre, tales como la seguridad contra el desalojo, y dedique más recursos públicos a mejorar la carrera policial.
\end{abstract}

Palabras clave: Seguridad pública, securitización, policial, crimen, desigualdad social, violencia, Brasil.

\begin{abstract}
This paper examines public policies based on the idea that situations in areas of social deprivation threaten the security of all other urban residents. Using evidence from São Paulo, Rio de Janeiro and Salvador, the three biggest metropolitan cities of Brazil, where mano dura approaches frequently enjoy popular support, and significant reductions in poverty and social inequality have not reduced crime and violence, the analysis demonstrates the counter-

${ }^{1}$ Agradecimientos: La investigación en la que se basa este artículo, forma parte de un proyecto más amplio llevado a cabo con la ayuda de una beca de investigación de The Leverhulme Trust, titulado "¿Seguridad para todos en la era de la securitización?” Agradezco el generoso apoyo de la Fundación The Leverhulme, enfatizando al mismo tiempo que solo yo soy responsable de los argumentos de este artículo. También quiero dar las gracias a Daniela Miranda y Thiago Neri por su asistencia en las entrevistas llevadas a cabo en Salvador.
\end{abstract}


productive consequences of simple policies of repression, especially in the context of a neoliberal model of urban development based on "accumulation by dispossession" and a privatization of public power that militates against the success of police reform. The paper explores ways in which, despite new commitments to deliver social justice, the state remains part of the problem, together with the implications of differences in the organization of drug trafficking and the alternative forms of "pacification" offered by "the rule of crime". Criticizing a politics of securitization that prioritizes a theatrical war on delinquency that criminalizes poverty and drug addiction, the text argues for democratizing the production of public security policies, understanding what kinds of security poor people prioritize, such as security against eviction, and devoting more public resources to improving the police career.

Keywords: Public security, securitization, policing; crime, social inequality, violence, Brazil.

Referencia normalizada: Gledhill, J. (2013) La mala administración de la seguridad pública, en Revista de Antropología Social, 22: 25-57.

SUMARIO: 1. ¿Un paso adelante, dos pasos atrás? Desigualdad, seguridad y violencia. 2. Las complicadas relaciones entre el Estado y el poder criminal. 3. No hay soluciones fáciles: la UPP bahiana. 4. Conclusión: lecciones de la Bahía. 5. Referencias bibliográficas.

Cuando Dilma Rousseff, la primera mujer presidente de Brasil, se hizo cargo tras dos mandatos del presidente Luiz Inácio Lula da Silva a principios de 2011, su elección garantizó una continua mejora de las políticas de lucha contra la pobreza, que hicieron ganar a las administraciones anteriores del Partido de los Trabajadores (Partido dos Trabalhadores, PT), una popularidad no solamente nacional, sino internacionalmente aclamada. Sin embargo, el desarrollo brasileño sigue presentando notables paradojas y contradicciones. En este trabajo se utiliza un análisis crítico de las políticas de seguridad pública en los diferentes estados de la República Federal de Brasil como un medio para explorar los desafíos clave que el país todavía necesita superar.

\section{1. ¿Un paso adelante, dos pasos atrás? Desigualdad, seguridad y violencia}

Como actor diplomático cada vez más respetado en el escenario mundial, Brasil superó al Reino Unido en 2012 convirtiéndose en la sexta economía mundial más grande, al ver sus perspectivas económicas estimuladas por el descubrimiento de grandes yacimientos de petróleo. Sin embargo, los expertos financieros en la crisis que afligió Europa y sus homólogos estadounidenses coincidieron en el argumento que la economía brasileña sufría de graves deficiencias estructurales en términos de "competitividad" global que limitaría su crecimiento futuro. De hecho, dicho crecimiento perdió fuerza en 2012, contradiciendo las predicciones gubernamentales en el tercer trimestre, a pesar de nuevas medidas de estímulo. Dichos críticos a menudo defendieron el enfoque adoptado por México, la segunda economía de Latinoamérica, cuya reciente mejora del crecimiento fue vista como una consecuencia de la reducción de los costes salariales a niveles más competitivos con respecto a los de 
China, donde los salarios reales estaban aumentando. Una lectura más crítica de las políticas mexicanas mostraría que la transferencia de ingresos que va desde la mano de obra al capital, es tanto más probable que tenga lugar ahora, en cuanto que el Congreso ha aprobado una "reforma" de la legislación laboral que reduce los derechos de los trabajadores y permite que los empleadores se beneficien más de prácticas tales como la subcontratación. México es el país de América Latina donde más han aumentado la desigualdad y la concentración de los ingresos y donde menos se ha reducido la pobreza a lo largo de la última década² ${ }^{2}$ La mayoría de sus ciudadanos no se han beneficiado, pues, de la mejoría de las tasas de crecimiento económico. Esto apenas cambiaría en el caso de un modelo económico que se definiera como una "carrera global a la baja", al menos pensándolo desde el punto de vista del tipo de sociedad que puede construirse en base a una economía semejante.

Por contraste, en 2010 los brasileños votaron políticas que reducen el desempleo, fomentando la sustitución del trabajo en el sector informal por empleo formal con acceso a beneficios estatales, permitiendo así que los salarios reales aumenten. Aunque el aumento de las exportaciones agrícolas ha contribuido significativamente a la economía, el gobierno del PT continúa con sus políticas en favor del trabajo, permitiendo que el mercado interno crezca, y que esto, junto con la inversión del sector público, sea la clave para mantener el crecimiento. Frente a ello, el modelo europeo de programas de "austeridad", económicamente contraproducentes, son incompatibles con la obligación del gobierno de mejorar la justicia social eliminando la pobreza. Una década de gobierno federal encabezado por el PT ha reducido significativamente el número de brasileños que viven en la pobreza, del $37,5 \%$ al $20,9 \%$ de la población en 2011, y ha reducido a más de la mitad la pobreza extrema, hasta el 6,1\% (CEPAL 2012). Con el programa de Rousseff "Brasil sin Miseria" (Brasil sem Miseria), las transferencias de ingresos directas a las familias pobres con niños, prometen eliminar la indigencia por completo, pero la verdadera medida del éxito de las políticas brasileñas es la creación de un mayor número de puestos de trabajo pagados con salarios dignos, que permiten a muchas familias pobres salir por completo de la dependencia del conjunto de programas destinados a aliviar la pobreza, que han tenido un impacto significativo, no sólo sobre la pobreza, sino también sobre los niveles de desigualdad social ${ }^{3}$.

${ }^{2}$ Las cifras de CEPAL indican que la pobreza medida simplemente en términos de nivel de ingresos ha disminuido en México, pero sólo un 4,1\%, menos que en cualquier otro país de América Latina, mientras que la indigencia había en realidad aumentado: ésta se situaba en el $13,3 \%$ en 2011, en contraste con el 12,6\% de una década antes, (CEPAL 2012).

${ }^{3}$ El coeficiente de desigualdad en la distribución de ingresos de Gini fue del 0.604 en los primeros años de la década de 1990 en Brasil, cayendo al 0.587 hacia el final del la administración de Frenando Enrique Cardoso, y alcanzando el 0.5687 al final de 2004 (Ivo, 2008:191). Aunque todavía era elevado, la tendencia a la reducción de la desigualdad en los ingresos mensuales era evidente en todas las regiones, tanto para los hombres como para las mujeres, en el 2007 se cifraba en 0.534 y el ritmo de reducción estaba aumentando, llevando a algunos analistas a sugerir que la desigualdad brasileña en los ingresos podría converger con la de Europa occidental en una década (Soares, 2008). Dado que Francia tiene un coeficiente de Gini del 0.308 hay aun un largo camino para estrechar la brecha, pero las políticas de austeridad europeas pueden ponerlo 
La movilidad social cesó durante las dos décadas de ajuste estructural neoliberal — privatizaciones, reestructuración de los mercados laborales y precarización del trabajo (Druck 2011) - , pero volvió a darse en Brasil con Lula (Pochman 2009). Casi 24 millones de brasileños, en su mayoría jóvenes y bastantes negros, han ascendido a la clase "C" formada por personas que ganan entre 4 y 10 salarios mínimos. En la actualidad, sería un error sociológico el describir a este grupo como una "nueva clase media". La entrada en el mundo del consumo masivo y el acceso a los préstamos hipotecarios no borran las ventajas sociales acumuladas que las "viejas" clases medias han adquirido mediante la educación privada primaria y secundaria, el acceso más fácil a la educación superior gratuita y la pertenencia a redes sociales que facilitan la entrada en la carrera profesional (Souza 2009). En una sociedad en la que las diferencias de estilo de vida se mantienen a través de las formas residenciales, del uso del espacio público, así como mediante los prejuicios que asocian la raza a la clase social — que siguen siendo importantes a pesar de los programas de acción positiva y del cambio de la opinión pública_- "sentirse" de clase media no es lo mismo que tener suficiente dinero para tomar un avión con destino a una ciudad lejana en lugar que el autobús. La desigualdad se ha reducido en términos de salarios, no en capital, y el capital tiene innumerables dimensiones no económicas. Sin embargo, el desarrollo reciente de Brasil contrasta fuertemente no sólo con el de México, sino también con el de los Estados Unidos e incluso con el de bastantes países europeos, (Stiglitz, 2012).

A pesar de todo, Brasil no sólo sigue siendo una sociedad muy desigual, también sufre de severos déficits en la provisión de salud pública y educación, tal que en 2011 lo dejó en la posición ochenta y cuatro (de un total de 187 países) en la clasificación de Indicadores Internacionales sobre Desarrollo Humano del Programa de Naciones Unidas; no sólo por debajo de México, sino también por debajo del promedio para toda la región de América Latina (PNUD, 2011). Por otra parte, Brasil es un país muy violento. De acuerdo con la ONG mexicana Seguridad, Justicia y Paz, si medimos la violencia en términos de las tasas de homicidio, 40 de las 50 ciudades más violentas del mundo en 2011 se encuentran en América Latina, 14 de ellas en Brasil (Seguridad, Justicia y Paz, 2012). Maceió, capital del estado de Alagoas, en la región Nordeste de Brasil, ocupó el tercer lugar en el ranking mundial, con una tasa de homicidios menor que la de San Pedro Sula, Honduras, y que la de Ciudad Juárez, México, pero, junto con Belém la capital de Pará en la región norte, es más violenta que Acapulco en México, la capital venezolana, Caracas, y que Cali y Medellín en Colombia. Es cierto que las dos mayores ciudades metropolitanas de Brasil, Río de Janeiro y São Paulo, ya no aparecen en este ranking. En 2011 sus tasas de homicidio parecían acusar una fuerte tendencia de descenso (Instituto Sangari, 2012). No obstante, a principios de noviembre de 2012 en São Paulo, una avalancha diaria de asesinatos-ejecuciones produjo un aumento del $90 \%$ en los índices de

más fácil: el coeficiente de Gini de Gran Bretaña, del 0.34, estaba en lo más alto en treinta años en 2011 (para mayores detalles, véase: http://www.poverty.org.uk/09/index.shtml, acceso 28 de noviembre de 2012). El índice de Gini brasileño, en contraste, había descendido otra vez al 0.501 (IGBE, 2011). 
homicidios respecto a las de septiembre y octubre del año anterior, hasta alcanzar una cifra total mensual de víctimas mortales de más del doble que la registrada en Ciudad Juárez en ese momento (Leblon, 2012). Paradójicamente, en noviembre de 2012, el número de víctimas de Ciudad Juárez, había caído sustancialmente con relación a los máximos asociados a la espectacular narco-violencia que hizo a la ciudad tan tristemente célebre entre 2009 y 2011. Las autoridades atribuyeron dicho descenso a la transferencia de la seguridad desde la Policía Federal a una fuerza policial municipal reformada y comandada por un militar retirado, Julián Leyzaola. La estrategia de "mano dura" de Leyzaola trasladó la violencia del centro de la ciudad a los barrios periféricos de bajos recursos, aunque también provocó crecientes quejas contra la policía por las violaciones de derechos humanos y por las ejecuciones extrajudiciales (Patterson, 2012).

Incluso esta simple comparación, nos muestra que las mediciones cuantitativas unidimensionales, tales como el número de homicidios por cada 100.000 habitantes, no logran captar le modo en que la naturaleza de la violencia letal varía en diferentes momentos y en diferentes lugares. El nuevo ciclo de violencia en São Paulo, que comenzó en julio de 2012 y que en muchos aspectos se parece al estallido anterior de violencia del 2006, fue provocado, como veremos en la siguiente sección, por una escalada de enfrentamientos entre la policía y la principal organización criminal que operaba en la ciudad y en el interior del Estado de Sao Paulo: el PCC (Primeiro Comando da Capital). La reducción de la violencia en Ciudad Juárez, por el contrario refleja un retorno al antiguo escenario de violencia entre los miembros de las bandas locales y la policía ejecutora de asesinatos extrajudiciales en vecindarios pobres; lo que se acerca más a la naturaleza de la violencia que se produce en la periferia urbana de Maceió. Por lo tanto, es importante comprender los perfiles sociales particulares de la violencia homicida en los diferentes lugares; esto es, cuáles son los grupos más directamente afectados por las formas específicas de violencia, en términos de clase, de zona de residencia, de género, de raza o de otras variables sociales, todo lo cual queda oculto tras las generalizaciones estadísticas.

En el contexto brasileño, un asunto que causa gran preocupación es el desplazamiento de Salvador de Bahía del vigésimo noveno lugar al vigésimo segundo en el ranking de ciudades más violentas de 2011. Aunque Bahía se ha beneficiado en gran medida de las políticas federales de reducción de la desigualdad social y de expansión de las oportunidades de empleo - lo que permitió al gobernador del estado PT, el sindicalista Jacques Wagner, lograr su reelección para un segundo mandato en 2010 - el crimen y la violencia ha continuado en aumento. Con una región metropolitana que alberga 3,5 millones de habitantes y una tasa de casi 60 homicidios por cada 100.000 residentes, la cifra absoluta de muertos por homicidios de Salvador en 2011, fue superior a la de cualquier otra metrópoli de América Latina, que no sean Caracas y Ciudad de Guatemala de similar tamaño (Seguridad, Justicia y Paz, 2012). El estado de Bahía estaba en el séptimo lugar a nivel nacional en términos de muerte por la violencia, y en el primer lugar de muertes causadas por armas de fuego (Instituto Sangari, 2012). Aunque el tráfico de drogas ocupa un lugar central en los patrones de violencia, otros tipos de delitos, como el robo de vehículos, 
asaltos a bancos, asaltos a autobuses, el secuestro y la extorsión, también están aumentando. La violencia física tiende a ser consustancial a todos estos crímenes. Una víctima que "reacciona" a un asalto -incluso a través de un gesto de enojo en lugar de la resistencia activa - puede ser fácilmente asesinada, especialmente en la actualidad cuando los ataques involucran más armas de fuego, a menudo en manos de adolescentes.

El crimen sexual, incluyendo el tráfico de menores para el turismo sexual y la violación dentro y fuera de los contextos domésticos - muchas de las cuales siguen sin denunciarse-, constituyen otra de las mayores preocupaciones ${ }^{4}$. Están surgiendo patrones inquietantes de violencia sexual, tanto entre mujeres como entre varones adolescentes de barrios pobres, a edades tan tempranas como los 15 años, incluidos apuñalamientos motivados por los celos de novios infieles, y en un caso reciente, la tortura sistemática de una niña llevada a cabo por la parte ofendida y filmada con un teléfono móvil. Desde que, tanto la participación en el tráfico de drogas como la actividad sexual, comienzan a una edad temprana, podría especularse acerca de sus interconexiones, aunque las culturas neoliberales de producción del yo a través del consumo también podrían desempeñar un papel. No obstante, fue la tasa de homicidios la que figuraba prominentemente en la formulación de nuevas políticas de seguridad, por parte del gobierno estatal controlado por el PT, para la región metropolitana de Salvador y el resto de Bahía.

Aunque sería injusto acusar a las autoridades de la falta de atención a otros tipos de violencia, incluida la violencia contra las mujeres cual es objeto de un programa especial, la actual política pública de seguridad de Bahía está fuertemente estructurada en función de la relación entre homicidio y narcotráfico en los barrios más pobres de la ciudad. El programa del gobierno del estado "Pacto por la Vida" (Pacto pela Vida) busca disuadir a los jóvenes del consumo de drogas y de su participación en el tráfico, pero el principal énfasis está puesto en las medidas destinadas a "reducir los delitos contra la vida y contra la propiedad" a través de nuevos modelos de vigilancia policial implantados en el interior de comunidades pobres, consideradas con altos niveles de violencia y criminalidad. El peligro de este enfoque es que señala comunidades particulares como la fuente de la delincuencia y la violencia de toda una ciudad, transformando sus problemas sociales de pobreza, la falta de claridad en la titularidad de las tierras y bienes y las deficientes infraestructuras y condiciones de vida, en los problemas que amenazan la seguridad de todos los residentes de la ciudad. Tal "securitización" de los problemas sociales conlleva el peligro de cortar con la misma tijera a todos los residentes de estos barrios, así como el de acrecentar lo que Loïc Wacquant (2007) denomina "estigmatización territorial" que parece emerger del lugar de residencia, y que a menudo repercute negativamente, por ejemplo, en las perspectivas de empleo de los que lo habitan.

${ }^{4}$ Durante 2012 algunos episodios destacados, que recibieron una amplia difusión, fueron la violación en serie de dos jóvenes mujeres por los miembros del grupo musical New Hit dentro del bus de la banda, y el asalto sexual perpetrado sobre una Fiscal mientras ella y un juez a quien acompañaba a tomar una copa en un bar de un barrio de clase alta fueron retenidos durante doce horas por una banda de secuestradores adolescentes. 
La Secretaría de Seguridad Pública de Bahía (SSP), encabezada por el delegado de la Policía Federal Maurício Teles Barbosa, de 34 años en el momento de su nombramiento en enero de 2011, ha dado a sus operaciones contra el tráfico de drogas un alto perfil público mediante la publicación de los rostros de los traficantes más importantes en una "baraja" virtual (baralho do crime), publicada en periódicos e Internet. Diseñado para fomentar las denuncias anónimas, como parte del objetivo general de Pacto pela Vida en "acercar a los ciudadanos a la policía", esta medida permite igualmente a los periódicos destacar los éxitos policiales en el apresamiento de los criminales "más buscados"; aunque en un caso, casi cómico, fue la amante de un traficante fugado de la cárcel quien facilitó su captura al apuñalarlo por infidelidad. Las nuevas actividades de inteligencia dejan a un lado, no obstante, el empuje principal de las nuevas políticas de seguridad públicas de Bahía reproduciendo el programa de "pacificación de favelas" iniciado por el gobierno del estado de Río de Janeiro en la Favela Santa Marta, en la zona sul, en noviembre de 2008, y continuado en la cinematográficamente famosa Cidade de Deus, en la zona oeste, en febrero de 2009.

La caída de las tasas de homicidio en Río de Janeiro se atribuye con frecuencia a la implementación de las "Unidades de Policía pacificadora" (UPP) que proporcionan una presencia permanente de la comunidad policial en las favelas a continuación de una operación de "ocupación" inicial que, supuestamente, limpiaría el barrio de traficantes. A finales de 2012, 28 favelas de Río tenían UPP. Las autoridades bahianas utilizan el nombre de "Bases Comunitarias de Seguridad" (Bases Comunitarias de Segurança, BCS) en lugar de UPP. Bahía es el único estado, aparte de Paraná — cuyas unidades se llaman Unidades Paraná Segura, UPS—, en haber seguido el enfoque de Río de Janeiro hasta la fecha, y su programa está menos avanzado en términos de implementación. El primer BCS fue inaugurado en el pequeño asentamiento de Calabar en abril de 2011, una isla de pobreza en una próspera zona de Salvador, y no fue hasta octubre del mismo año que se instalaron tres nuevas bases en el gran complejo de asentamientos irregulares conocidos como Nordeste de Amaralina, con una población de 120.000 habitantes. La puesta en funcionamiento se retrasó en 2012, pero a finales de noviembre, se habían instalado once bases, dos de ellas situadas fuera de la región metropolitana de Salvador. La instalación de las bases se aceleró cuando la campaña electoral de las municipales de 2012 estaba candente. Las cuestiones de seguridad ocuparon un lugar destacado en la finalmente exitosa campaña contra el candidato del PT de ACM, Neto, líder del ala derecha de los Demócratas, y así llamado porque es el nieto de la figura más importante de la política bahiana de la segunda mitad del siglo XX, el difunto Antônio Carlos Magalhães, tres veces gobernador, ministro del gabinete federal y senador.

La improvisación políticamente motivada en la implementación de las nuevas políticas de seguridad en Bahía ha creado indudablemente sus propios problemas, pero en lo que sigue sostengo que operan profundas contradicciones, no sólo en Bahía, sino en Brasil en su conjunto. Para poner de manifiesto la naturaleza de dichas contradicciones, en la sección siguiente utilizo fuentes secundarias y notas de prensa para analizar las diferencias y similitudes entre la situación de las ciudades 
metropolitanas de Río de Janeiro y São Paulo, antes de volver, en la tercera sección, a un análisis más detallado de Salvador, la ciudad en la que he hecho mi propia investigación etnográfica.

\section{Las complicadas relaciones entre el Estado y el poder criminal}

Teniendo en cuenta las cifras de muertos y la potencia de fuego involucrada, se ha convertido en algo común comparar la violencia asociada con el tráfico de drogas en Brasil con una "guerra" e, incluso, el hablar de la necesidad de combatir la "insurgencia" del crimen organizado. Es verdad que en ciertos momentos la violencia perpetrada por criminales contra la policía parece más agresiva que defensiva, incluso alcanzando una forma de "terrorismo", en el sentido que es intencionalmente espectacular y diseñada para provocar el miedo entre el público en general. Ello proporcionaría una lectura superficial de la violencia perpetrada por el PCC en São Paulo en 2006. Sin embargo, no captaría la lógica subyacente de lo sucedido en 2006, o el por qué la historia parecería repetirse seis años después.

Originalmente creado en el interior de las prisiones en las que sus líderes estaban encarcelados, las operaciones del PCC en el "exterior" siguen siendo dirigidas desde el interior de las cárceles que controla la organización. Lo que convierte en distintiva la fuerza del PCC en el tráfico de drogas brasileño, es no solo que ha logrando una hegemonía casi indisputable sobre el narcotráfico en São Paulo, sino que también ha tenido éxito en el establecimiento de un fuerte control de la vida social de la periferia urbana de São Paulo, incluyendo la capacidad de declarar el toque de queda. Administrando su propio tipo de justicia en las zonas abandonadas por el estado, el PCC provee a los residentes de un tipo de seguridad a través de prácticas, de las cuales tenemos a día de hoy detalladas evidencias etnográficas, gracias a la labor de estudiosos brasileños, como Vera Telles y Gabriel Feltran (véase, por ejemplo: Telles, 2010; Feltran, 2010a). Los ladrones que roban a sus vecinos, así como los violadores, tienden a ser tratados con dureza, pero "la ley del crimen" administrada por el PCC no es una justicia sumaria, en tanto se basa en la argumentación a favor y en contra de los acusados, en el marco de procedimientos deliberativos conocidos como "debates". Feltran (2010a: 111) sostiene que los debates no sólo imitan el sistema de justicia oficial, sino que también han "ocupado el espacio legítimo del aparato de violencia previamente regulado por las prácticas de la 'justicia popular', tales como los linchamientos y los pagos a asesinos". Volveré sobre este aspecto de la organización del PCC en la siguiente sección, ya que otra característica inusual del PCC ha sido su habilidad para extender su influencia a otros estados, entre los cuales Bahía es actualmente quizás el ejemplo más importante, aunque la violencia de São Paulo del 2012, se reprodujo también en el estado de Santa Catarina, al sur. Pero de inmediato quedará claro que la hegemonía del PCC en la periferia urbana podría ayudarnos a comprender la disminución de las tasas de homicidio que tuvo lugar después de 2006 en São Paulo (Feltran, 2010b). La otra pieza del rompecabezas, que explica también la reanudación de la violencia en 2012, concierne a las relaciones entre el gobierno estatal, la policía y los traficantes. 
Tal como una profunda investigación de la ONG Justiça Global y un equipo de la Facultad de Derecho de Harvard ha demostrado, la causa del estallido de las hostilidades entre el PCC y la policía en el 2006 fue la extorsión practicada por la policía contra los familiares de líderes encarcelados del PCC (Ribeiro et al., 2011). La violencia se intensificó debido a que la policía respondió con una campaña de ejecuciones extrajudiciales que dejaron 120 muertos — comparados con 48 policías-. Aquella terminó después de que un helicóptero de la policía militar llevara a un funcionario superior y al abogado del carismático líder ${ }^{5}$ del PCC Marcos Willians Camacho, alias "Marcola", a la penitenciaría en la que estaba encarcelado este último. Aunque la negociación de un acuerdo de alto el fuego sigue siendo negada oficialmente, parece que el gobierno del estado acordó permitir a los líderes del PCC continuar controlando las cárceles y barrios periféricos. La reanudación de la violencia en 2012 se produjo tras dos violentas redadas policiales en reuniones del PCC que tenían lugar en la periferia urbana, una de ellas un "debate". En el primer caso seis, y en el segundo nueve, personas fueron ejecutadas en una clara violación del acuerdo de que la policía no haría daño a cualquier criminal que se entregase (Martins, 2012). Peor aún, el gobernador del estado, Geraldo Alckmin inicialmente pareció respaldar este cambio de política, aunque posteriormente se vio obligado a hacer una firme condena de una ejecución policial que fue filmada por una persona desde una casa al otro lado de la calle. Otra inquietante revelación fue que se supo que algunos agentes de policía habían vendido al PCC listas informatizadas que contenían los nombres completos, números de teléfono y las direcciones de algunos de sus colegas, sumándose esto a los riesgos que enfrentan los miembros en servicio y retirados de las fuerzas y sus familias ${ }^{6}$.

Cuando es la corrupción policial la que desencadena las hostilidades, o la policía mata sin intentar capturar a los delincuentes, es difícil establecer la simple distinción entre acción agresiva y defensiva, que la metáfora de la "insurgencia" criminal sugiere. Pero más significativo aún, el caso de São Paulo no sólo sugiere que la violencia policial puede ser parte del problema más que una posible solución a los del crimen y la inseguridad, sino que el propio estado puede ser parte del mismo 7 . Desarrollaré esta línea de análisis, volviendo al caso de Río de Janeiro.

La organización del tráfico de drogas en Río es muy diferente de la de São Paulo. Michel Misse (1997) ha hecho hincapié en que el control del tráfico de drogas en

\footnotetext{
${ }^{5}$ Para un análisis del hábil uso publico del lenguaje de la privación, los derechos y la justicia social de Marcola, véase: Holston, 2008.

6 "Corregiduría sospecha que policías venden datos de PMs a bandidos", Folha de São Paulo, 13 de noviembre 2012.

${ }^{7}$ El opositor Partido de la Social Democracia Brasileña (PSDB), controla el estado de San Pablo, aunque el candidato del PT ganó las elecciones municipales de 2012 contra el último candidato presidencial del PSDB, Jose Serra. Más o menos el mismo grupo de políticos y autoridades que gobierna actualmente el estado, estuvo a cargo de 2006 acontecimientos y, de acuerdo con el informe de Justiça Global, no hicieron nada para disciplinar a los oficiales culpables en tales ocasiones, ni se hicieron presentes en las continuas causas de quejas, tales como las relativas a las condiciones deplorables, dentro de un sistema de prisiones que San Pablo sigue ampliando con un celo solo igualado en pocos otros lugares más allá de los Estados Unidos.
} 
las favelas de Río de Janeiro está muy fragmentado, y este análisis también se aplicaría a Bahía a pesar de la presencia allí del PCC. Hubo una etapa inicial, a partir de finales de la década de 1970, cuando una sola organización, el Comando Rojo (Comando Vermelho), controlaba el tráfico de drogas en la ciudad. Pero diez años después, el panorama era el de una frecuente competencia violenta entre una serie de organizaciones, con bandas locales ejerciendo un precario control armado sobre territorios altamente segmentados. Irónicamente el Comando Vermelho surgió como una consecuencia no deseada de la dictadura militar, que puso a los presos políticos en las mismas celdas que a los delincuentes de poca monta que hasta ese momento carecían de organización y estrategia, y como Misse (1997) y André Moysés Gaio (2006) han enfatizado, la represión estatal ha seguido desempeñando un papel central en la construcción de la delincuencia en la época de la fragmentación.

El nivel de represión policial se incrementó después de que el populista Leonel Brizola terminara su segundo período como gobernador del estado de Río en 1994. Brizola, que ahora buscaba una base política tanto entre los pobres de la ciudad no organizados como entre los trabajadores organizados, y combinaba objetivos humanitarios con pragmáticas prácticas clientelistas, favoreció la provisión de servicios e infraestructuras sobre los esfuerzos para desalojar a las personas cuya ocupación de la tierra era ilegal, y detuvo las acciones policiales represivas en sus comunidades. Aunque la derecha política culpó a Brizola por entregar las favelas al control del narcotráfico, la renovación de la represión policial por parte de sus sucesores, no consiguió la victoria de "la ley y el orden". Por el contrario, el cambio de la política aumentó las oportunidades disponibles para la policía de Río de hacer dinero mediante la venta de drogas confiscadas, y también mediante la venta de armas a los mismos criminales que debían perseguir. Aun cuando la policía perseguía realmente a los traficantes, a menudo simplemente extorsionaban a los criminales por dinero a cambio de dejarlos marchar libres. Tampoco fue la corrupción policial la única causa de la constante expansión de la economía informal, los mercados ilegales y delictivos en los que participaron agentes estatales: dentro de este marco también se negociaban "bienes políticos" (Misse, 1997). Como Enrique Arias (2006) mostró en profundidad a través de sus investigaciones etnográficas en tres favelas de Río, los criminales locales no solo forjan entre bambalinas relaciones clientelares con los líderes "legítimos" de la comunidad y con organizaciones tales como las iglesias, ONG y asociaciones de vecinos, sino que extienden sus redes más allá de la comunidad para incluir a políticos "respetables" que proveen protección a cambio de los servicios de los traficantes en la movilización de votos para las elecciones - $\mathrm{o}$ impidiendo hacer campaña a los rivales-.

Tal como el antropólogo y escritor Luiz Eduardo Soares (2006) ha señalado, es poco probable que las políticas públicas de seguridad vayan a beneficiar a las personas que realmente viven en las favelas, mientras los límites entre la policía y los criminales se difuminen como dos caras de la misma moneda, que es exactamente cómo desde hace tiempo los ciudadanos más humildes tienden a considerar el asunto (Caldeira, 2002). Soares fue brevemente secretario de estado para la seguridad pública en Río de Janeiro, hasta que el gobernador Anthony Garotinho 
lo destituyó en 2000. Él abogó por un nuevo modelo de política comunitaria en las favelas, vinculadas a proyectos de desarrollo social. Parece que el verdadero éxito de estos primeros experimentos del sistema tipo UPP fue lo que condujo a su eliminación, como consecuencia de la presión del alto mando policial respaldado por políticos que se habían beneficiado de su manipulación del "mercado político informal, ilegal y criminal" de Misse (Arias, 2006:36). La retirada de las nuevas unidades policiales no sólo permitió a los traficantes volver, sino que provocó también "ajustes de cuentas" con aquellos que habían dado la bienvenida a la presencia del estado. Sin embargo, desde 2008, el nuevo programa de UPP ha sido perseguido vigorosamente por el gobierno del estado de Río, de Sergio Cabral, que pertenece al centrista Partido del Movimiento Democrático Brasileño (PMDB), principal aliado del PT a nivel federal, aunque aliado con los oponentes del PT en Bahía ${ }^{8}$. Su actual secretario de Seguridad Pública, José Mariano Beltrame, ha demostrado ser un defensor efectivo del programa, asegurando a un público escéptico que esta vez la policía está en las favelas para quedarse el tiempo que sea necesario ${ }^{9}$. En particular, Beltrame ha rechazado dos cuestionamientos: uno considera que el objetivo real del programa del UPP es hacer que la ciudad parezca segura para los visitantes -y para las clases medias - , mientras se prepara para la Copa del Mundo de 2014 y los Juegos Olímpicos del 2016, y que será abandonado después de que dicho propósito se haya cumplido; el otro, es que el programa está diseñado para facilitar procesos a más largo plazo de desposesión y gentrificación. En la medida en que muchas de las favelas de Río de Janeiro se encuentran junto a barrios de clase alta y ocupan colinas con hermosas vistas, en lugares donde los turistas extranjeros estarían encantados de alquilar casas, incluso antes de su "pacificación" (Handzic, 2010), aquella no es, pues, una idea completamente extravagante.

Comencemos, sin embargo, con las aparentes ventajas del modelo de UPP como una alternativa a la represión policial. Según los datos recogidos por el Observatorio Internacional de la Violencia y Narcotráfico (Observatório Internacional de Violência e Narcotráfico, Obivan), financiado por la Fundación Soros Open Society, las redadas policiales han sido responsables de más de la mitad de los violentos enfrentamientos producidos en las favelas de Río de Janeiro antes de la introducción de las UPP. En consecuencia, la policía también ha sido responsable de la mayor parte de los "daños colaterales" causados por tiroteos con los traficantes o, como también ocurre con frecuencia en Salvador, por los disparos indiscriminados en lugares públicos por parte de agentes nerviosos. Esto llevó a Benjamin Lessing,

${ }^{8}$ Cabral y Garotinho, originalmente un protegido de Brizola, son enconados enemigos políticos. Garotinho utilizó sus contactos en la policía militar para hacerle la vida difícil a Cabral, secundando una huelga de bomberos (pertenecientes a la misma corporación). Logró posteriormente ser visto manos a la obra en la huelga por la policía militar de Bahia, lo que causó problemas al gobernante PT allí, en febrero de 2012. En ambos casos los huelguistas recurrieron a tácticas militantes, las cuales en el caso de Bahía claramente cruzaron la línea de la legalidad y fueron algo más que una mera reminiscencia del modo en que el PCC conduce estos temas.

9 "Hoy la UPP está en manos de la sociedad, dice Beltrame", entrevista con Júlia Dias Carneiro, http://www.bbc.co.uk/portuguese/noticias/2012/03/120314_beltrame_doha_jc.shtml, acceso 15 de marzo, 2012. 
coordinador de Obivan, a argumentar en una entrevista con la BBC de Brasil ${ }^{10}$, que las UPP ofrecen una estrategia más inteligente de "represión condicional". Desde el momento en que la ocupación de las favelas está preanunciada, los traficantes tienen la oportunidad de huir, e incluso si no lo hacen, no se verán perjudicados si se entregan sin recurrir a la violencia. Visto que la última promesa fue tácitamente hecha - y rota - por el Estado en São Paulo. El programa de UPP de Río difiere radicalmente del enfoque que las autoridades de São Paulo adoptaron como una política no declarada después del alto el fuego de 2006, puesto que se basa en los principios del estado de "recuperar" el control de los territorios perdidos, en manos de agentes armados no estatales, al tiempo que simultáneamente reasume la responsabilidad de mejorar el bienestar de los ciudadanos a los que había abandonado.

La instalación de una UPP es el segundo estadio del proceso que se inicia con la "reconquista" y "ocupación" del territorio perdido, normalmente llevada a cabo por unidades de la policía militar, principalmente del Batallón de Operaciones Especiales (BOPE) en el caso de Río, aunque la fuerzas armadas participaron en la ocupación de la gran favela Vila Cruzeiro y del Complexo Alemão a finales de 2010. A pesar de las preocupaciones de los comandantes en cuanto a que las tropas sucumbirían a las mismas tentaciones de corrupción que la policía si permanecían en las favelas, y de algunos episodios comprobados de robo y saqueo policial en las casas de los residentes durante operaciones en las que los agentes supuestamente andaban a la caza de traficantes, a primera vista, la política de pacificación evolucionó relativamente sin complicaciones. En noviembre de 2011, cuando las fuerzas de seguridad ocuparon Rocinha, una de las favelas más grandes y más visibles de Río de Janeiro, su principal capo de la droga, Antonio Francisco Bonfim Lopes, alias "Nem", fue incapaz de escapar a pesar de ofrecer un gigantesco soborno a la policía que lo descubrió escondido en el maletero de un coche perteneciente al Consulado de la República Democrática del Congo ${ }^{11}$. La policía federal posteriormente capturó a algunos de sus lugartenientes que habían pagado a contactos de la policía civil y militar para romper el cerco establecido en torno a la comunidad. Un dirigente de la Asociación de Residentes, vinculado a los traficantes y a una concejala del PSDB, no tardó en ser también arrestado ${ }^{12}$. Nem, de treinta y cinco años de edad, vinculado a la red criminal Amigos de los Amigos (Amigos de Amigos), había asesinado a su antojo en Rocinha. Es más, había logrado una enorme capacidad para sobornar a funcionarios públicos, y como consecuencia de la pacificación al menos se arrojó algo de luz sobre las redes políticas e incluso diplomáticas que le habían permitido ejercer sus negocios con total impunidad.

${ }^{10}$ Entrevista con Júlia Dias Carneiro, 23 de Diciembre 2011, http://www.bbc.co.uk/portuguese/noticias/2011/12/111222 rio_mexico_narcotrafico_jc.shtml, acceso 20 de marzo, 2012.

11 "Detenido Nem, el narcotraficante más codiciado de Río de Janeiro", http://internacional. elpais.com/internacional/2011/11/10/actualidad/1320910226_195850.html, acceso 10 de Noviembre, 2011.

12 "Ex-presidente de la Associação de Moradores de Rocinha es apresado", http://oglobo. globo.com/rio/ex-presidente-da-associacao-de-moradores-da-rocinha-preso-3367049, acceso 2 de diciembre, 2011. 
Sin embargo, a medida que pasaban los meses, los acontecimientos mermaron la euforia inicial. Se hizo claro que a pesar de que las principales operaciones de procesamiento de drogas podrían haber sido transferidas a otro lugar, el narcotráfico no había sido eliminado en Rocinha. Los asaltos y robos fueron en aumento: los residentes se quejaron a la prensa de que este tipo de cosas simplemente no sucedían cuando Rocinha estaba bajo la "ley del crimen"13.

El 26 de marzo de 2012, un líder comunitario fue asesinado a tiros. A pesar de que la presencia policial se había reforzado, y que los arrestos se hicieron después de haber recibido información de los residentes ${ }^{14}$, el mes siguiente trajo un intercambio de disparos entre la policía y los traficantes, que escaparon, y las quejas contra la policía comenzaron a aumentar ${ }^{15}$. El 21 de abril, una mujer residente acusó a tres agentes de tortura y violación ${ }^{16}$. Tres días después de este incidente y a partir de otros informes adicionales sobre disparos, 130 policías más fueron enviados a la zona. Estos agentes habían sido entrenados para patrullar a pie y usar técnicas adecuadas para la construcción de relaciones de confianza con los residentes ${ }^{17}$. Pero justo una semana antes de que la base policial permanente estuviera lista para ser inaugurada en septiembre, con un complemento planificado de 700 agentes, fue asesinado un policía militar. El gobernador Cabral trató de plantarle cara a los hechos al declarar que la violencia reflejaba la desesperación de los traficantes. Señaló que antes de la pacificación la policía era la invasora, y que ahora eran los "bandidos" los que ocupaban esa posición ${ }^{18}$. Aun así, el secretario Beltrame reconoció que muchos meses de ocupación no habían eliminado el "poder paralelo" de los traficantes dentro de la comunidad, y que "la pacificación es un trabajo que no ha terminado"19.

El modelo de la UPP presupone una transformación en el tipo de actuación policial dentro de las comunidades. Debe estar basado en programas especiales de capacitación en técnicas de policía comunitaria y en la participación diaria de la policía

13 "Los asaltos no ocurrían en Rocinha con el tráfico, dicen los habitantes", http://ultimosegundo.ig.com.br/brasil/rj/assaltos-nao-aconteciam-na-rocinha-com-trafico-dizem-moradores/ n1597410789553.html, acceso, 9 de enero, 2012.

14 "La policía identifica sospechosos de matar al líder comunitario de Rocinha", http:// g1.globo.com/rio-de-janeiro/noticia/2012/03/policia-identifica-suspeitos-de-matar-lider-comunitario-da-rocinha.html, acceso 30 de marzo, 2012.

15 "Policías y traficantes entran en confrontación en Rocinha", http://atarde.uol.com.br/ brasil/noticia.jsf?id $=5826624 \& \mathrm{t}=$ Policiais $+\mathrm{e}+$ traficantes + entram + em + confronto + na + Rocinha, acceso, 7 de abril, 2012.

16 "En declaración de 8 horas, PMs niegan agresión sexual en Rocinha", http://g1.globo. com/rio-de-janeiro/noticia/2012/04/em-depoimento-de-8-horas-pms-negam-agressao-sexual-narocinha.html, acceso 21 de abril, 2012.

17 "Después de una semana de violencia, Rocinha gana refuerzos de 130 PMs en prácticas", http://g1.globo.com/rio-de-janeiro/noticia/2012/03/apos-semana-de-violencia-rocinha-ganhareforco-de-130-pms-em-estagio.html, acceso 24 de abril, 2012.

18 "La policía coge a sospechoso de participar en la muerte de PM en Rocinha", http://oglobo.globo.com/rio/policia-prende-suspeito-de-participar-da-morte-de-pm-na-rocinha-6090780, acceso 14 de septiembre, 2012. El sospechoso en cuestión era un menor.

19 "Río refuerza la seguridad para inaugurar UPP en Rocinha", Folha de São Paulo, 21 de septiembre, 2012. 
en los programas de desarrollo comunitario diseñados para hacer que los residentes sientan que el gobierno se preocupa por ellos, que trata de mejorar sus perspectivas de empleo, sus oportunidades de educación, y sus niveles de vida. El lenguaje oficial presenta la "pacificación" en términos de recuperación, por parte del estado, del control de un territorio perdido a los criminales con el fin de "restablecer la plena ciudadanía" a los residentes que los traficantes armados aterrorizaban. Sin embargo, a pesar de los esfuerzos realizados para promover mejores prácticas en la vigilancia comunitaria, a través de programas de formación y auspiciando a las mujeres comandantes, los habitantes de la primera favela en recibir una UPP en Río, Santa Marta, inicialmente se quejaron de que la falta de consulta y participación de la comunidad no ayudó a mejorar su sentido de ciudadanía. En último término, el sentimiento de ciudadanía no es algo que pueda ser "dado" desde arriba, y el pretexto de la protección del medio ambiente utilizado para justificar la construcción de un muro de hormigón alrededor de esta favela, fue también ampliamente criticado por su falta de justificación racional (De Souza et al, 2009: 189). Sin embargo, los enfrentamientos violentos entre la policía y traficantes dejaron de producirse en Santa Marta. No puede decirse lo mismo de todas las UPP, y uno de los factores que pueden ser relevantes en el aparente éxito a largo plazo del programa UPP en Santa Marta, en términos de mejora de las relaciones cotidianas entre la policía y los residentes, puede ser el hecho que esta favela tenga un población comparativamente menor, 6,000 residentes (Cunha, 2012), consideración ésta igualmente relevante para la primera "UPP Bahiana" en Calabar. No obstante, un equipo de investigadores de la Universidad del Estado de Río de Janeiro fue capaz de demostrar la reducción de las tasas de homicidio en las comunidades cariocas con UPP, de hasta un $78 \%{ }^{20}$. Esto parece apoyar el principio de que "la represión condicional" y una presencia policial sostenida en la comunidad, ofrece mejores resultados que un simple modelo policial represivo.

Pero el modelo de la UPP aspira a hacer algo más que reducir los homicidios. Después de todo, en el caso de Sao Paulo, donde menos violencia es provocada por el conflicto entre los diferentes grupos por el control de la distribución de drogas, parece que las tasas de homicidio se pueden bajar simplemente permitiendo que los criminales gobiernen. En el caso de Río, aunque algunos residentes de las favelas han llegado a ver a la policía bajo una luz más favorable, también ha habido protestas de residentes contra ella, e incluso si los traficantes estuvieron detrás de algunos de esos incidentes, ello sería una prueba de su continua presencia en la vida social de esas comunidades. La policía continúa siendo asesinada en enfrentamientos con los traficantes en algunas de las comunidades "pacificadas", e igualmente siguen persistiendo tradicionales formas de corrupción policial. A principios de diciembre de 2012, la policía federal detuvo a un diez por ciento de la totalidad del $15^{\circ} \mathrm{Ba}$ tallón de la Policía Militar de Río de Janeiro, 63 agentes, por recibir pagos de los traficantes y por vender armas en el área de las trece favelas de Duque de Caxias ${ }^{21}$.

20 "Nueva realidad en las favelas: 250 vidas ahorradas", http://oglobo.globo.com/rio/novarealidade-nas-favelas-250-vidas-poupadas-6172735, acceso 26 de septiembre, 2012.

${ }^{21}$ Folha de São Paulo, 5 de diciembre, 2012. 
Algunos agentes de las UPP han sucumbido también a la tentación, lo cual no es sorprendente si tenemos en cuenta las sumas de dinero que hay en juego ${ }^{22}$. El ex comandante de la UPP de Morro de São Carlos fue arrestado en febrero de 2012 acusado de recibir de los traficantes pagos semanales de 15.000 reales (6.600 euros), después que las investigaciones de la policía federal revelaron la existencia de dichos pagos en varias UPP.

Por el lado positivo, una gama mayor de proyectos sociales del gobierno y de las ONG, así como oportunidades de capacitación, están hoy disponibles en las favelas en las que la pacificación se ha consolidado. Por otra parte, la presencia intensificada del estado no es pura bendición, en particular para los residentes pobres, por ejemplo desde el momento en que ya no es posible llevar la electricidad de la red pública sin pagar por ella. Cuanto más mejora la infraestructura de los asentamientos irregulares y más pacíficas se vuelven las comunidades, más atractivas serán para los forasteros, en particular para los jóvenes extranjeros que tienen menos prejuicios para vivir en una favela que los brasileños de clase media ${ }^{23}$. Estos procesos de por sí continuarán haciendo subir los alquileres y empujando a las familias más pobres de las favelas situadas céntricamente, hacia otros lugares más periféricos.

Otra dificultad reside, no obstante, en que los presupuestos de los gobiernos estatales no son suficientes para transformar la policía en toda el área metropolitana, lo que significa que la mayoría de las favelas no recibirán UPP. Su patrón de distribución inicial fue consecuente con la sospecha de que la seguridad de la ciudad para el turismo deportivo global era la primera prioridad; pero otro problema con la limitada cobertura es que los delincuentes expulsados de los asentamientos pacificados pueden lograr establecerse en otras regiones desplazando violentamente a aquellos que actualmente las controlan, antes que buscar un refugio pacífico en otros lugares dominados por parientes o miembros de la misma facción criminal. El secretario Beltrame insiste en que la mayoría de los soldados rasos de las bandas de narcotraficantes se verán obligados a permanecer en sus comunidades de origen, por lo que la migración no es un gran problema, pero los datos comparativos de Bahía invitan al escepticismo sobre dicha afirmación, como veremos más adelante. Pero en lo que respecta a asegurar el tipo de reforma que eliminaría la corrupción policial y que garantice el respeto de los derechos humanos, el mayor desafío reside en mejorar los salarios y las estructuras de la carrera profesional. La división de la policía en un brazo ejecutivo militar, y uno civil de investigación, es otro problema, pero el tema salarial es crucial ya que el sueldo relativamente bajo es sostenible, porque a la policía se le permite hacer otros trabajos remunerados en sus horas libres, incluyendo los ofertados en los servicios de seguridad privada.

Esto refuerza una tendencia a la apropiación del poder público por parte del poder privado, lo que excede con mucho la práctica normal del propietario de una tienda en los barrios de lujo que ofrecen al policía de servicio una propina para que

22 "Ex-comandante de UPP de São Carlos es apresado por implicación en el tráfico", http:// oglobo.globo.com/rio/ex-comandante-da-upp-do-sao-carlos-preso-por-envolvimento-com-trafico-3987256, acceso 16 de febrero, 2012.

23 "Pacificada, favela atrae habitantes extranjeros", Folha de São Paulo, October 28, 2012. 
cuide especialmente su propiedad. Así las cosas en Río de Janeiro, lo que presenta un desafío a la política de seguridad pública, no es simplemente un territorio controlado por narcotraficantes, ya que algunas favelas han sido tomadas por milicias armadas que expulsan a los traficantes sólo para imponer sus formas de extorsión a la comunidad a través de la venta de protección o del cobro de "peajes" en las ventas de bienes y servicios como televisión por cable y el gas (Zaluar y Conceição, 2007). Los milicianos pueden ser agentes de policía jubilados o fuera de servicio, y las milicias han servido también como base del poder de los políticos locales, replicando el tipo de servicios políticos que los traficantes y líderes comunitarios ofrecen en otros lugares. El secretario Beltrame reconoce que las milicias reproducen la lógica de captura y control del territorio de las UPP, pero sostiene que sus esfuerzos para eliminarlas se ven obstaculizados por la ausencia de una definición jurídica clara de la actividad de las milicias como criminal ${ }^{24}$.

Otro problema es el continuo despliegue represivo de la policía contra los adictos a las drogas, tanto en Río de Janeiro como en São Paulo, donde se interpretó ampliamente la violenta limpieza de las "cracolândias" 25 de la ciudad como un movimiento para despejar la zona de cara a su reurbanización por un grupo de promotores inmobiliarios cercano a gobernantes municipales y estatales. Los desplazamientos forzados de ciudadanos de pocos recursos son cada vez más comunes. Raquel Rolnik, Observador Especial de la ONU para el Derecho a una Vivienda Digna, emitió una fuerte declaración en abril de 2011 sobre la falta de transparencia, diálogo y compensación económica en los desalojos vinculados a los preparativos para la Copa del Mundo y los Juegos Olímpicos en São Paulo, Río de Janeiro, Belo Horizonte, Curitiba, Porto Alegre, Recife, Natal y Fortaleza (Comisionado de Naciones Unidas para los Derechos Humanos, 2011). Sin embargo, no se trata simplemente que las demandas especiales de alojamiento de los mega eventos deportivos están impulsando el desplazamiento, como del excepcionalmente cruel desalojo de los 6000 hombres, mujeres y niños de sus hogares en Pinheirinho, en el interior del estado de São Paulo mediante la policía antidisturbios fuertemente armada, como se demostró al comienzo del año siguiente. Este desalojo fue resultado de una decisión judicial a favor de un especulador financiero de origen libanés, bien conocido por las acusaciones de lavado de dinero y tráfico de información privilegiada. Estos ejemplos de lo que la "defensa de los derechos de propiedad" puede significar en el sistema de justicia brasileño, indican una continuidad del autoritarismo en la cultura política, a pesar de los avances democráticos de las últimas tres décadas y de la promulgación de leyes que ordenan la consulta y la participación popular en la planificación urbana. Como señala Raquel Rolnik (2012), quien ha resumido más recientemente la situación general con respecto al "derecho a la ciudad" de las personas que viven en las favelas:

${ }^{24}$ Hoy la UPP está en manos de la sociedad, dice Beltrame”, entrevista con Júlia Dias Carneiro, http://www.bbc.co.uk/portuguese/noticias/2012/03/120314_beltrame_doha_jc.shtml, acceso 15 de marzo, 2012.

${ }^{25}[\mathrm{NT}]$ Así se denominan popularmente las zonas de consumo masivo de crack. 
En el momento mismo en que amplios recursos públicos están disponibles para la inversión en la urbanización de las favelas del país -a través del PAC (Programa de Aceleración del Crecimiento) de las favelas- lo que observamos es la disolución de foros y procesos participativos, la selectividad geográfica en las favelas a ser urbanizadas y procesos masivos de desahucio en el curso de la ejecución de proyectos y obras, con frecuencia mediante el uso de la violencia. Aún más grave es la falta de reconocimiento, por parte de las autoridades municipales, de la regularización de la ocupación como un "derecho" de los residentes, al ser tratado el tema como una "cuestión social" y, por lo tanto, sujeto a discreción, y en la mayor parte de los casos, a una falta de consideración equilibrada de este derecho a través de la implementación de alternativas sostenibles al desalojo (Rolnik, 2012)

Desde esta perspectiva, mientras que las UPP y las inversiones en infraestructura prometen una mayor seguridad para algunos de los pobres de las ciudades, otros se enfrentan a un nuevo tipo de inseguridad, la pérdida de su casa, y a la represión policial sin tregua, como resultado de otras políticas públicas. Analistas como Neil Smith (2002) y David Harvey (2005) han señalado que esto es apenas sorprendente, dado que la construcción y el sector inmobiliario son actualmente la fuerza dominante, económica y políticamente, en las ciudades metropolitanas brasileñas, cuyo desarrollo conlleva una cantidad sustancial de "acumulación por desposesión" facilitada por el estado, que Rolnik describe.

Paso ahora a explorar cómo los problemas examinados en esta sección se ponen de manifiesto en el caso de Salvador, Bahía. Esto no me permitirá llegar a conclusiones muy optimistas, pero indica lo que debe cambiar en las políticas públicas para mejorar la situación que tenemos actualmente.

\section{No hay soluciones fáciles: la UPP bahiana}

Mi investigación en Bahía se ha centrado en un barrio con unos 60.000 residentes formados por una invasión de tierras durante la década de 1980, cuando el país era gobernado todavía por los militares (Hita y Gledhill, 2010).

Los residentes de Bairro da Paz, como se llama ahora, tienen una especial sensibilidad sobre las cuestiones destacadas en el análisis de Raquel Rolnik. No poseen fuertes derechos sobre las tierras. Situado en una arteria principal de tráfico que une el aeropuerto internacional con el centro de la ciudad, al menos partes del asentamiento son vulnerables a la expropiación para dar paso a nuevos sistemas de transporte previstos para suavizar el movimiento de visitantes que vienen a la ciudad para la Copa del Mundo y aliviar problemas generales de congestión. Además su mayor problema es que se trata de una comunidad de personas pobres cuyos alrededores antes vacíos han sido ahora invadidos por una población de clase media y alta. Los nuevos condominios están presionando contra las fronteras de una comunidad que ahora parece fuera de lugar en términos de la forma de vida que el desarrollo que esta parte de Salvador se supone que ofrece. La saliente administración municipal, no del PT, que gobernó la ciudad hasta el final de 2012 fue notoriamente útil para los promotores inmobiliarios, al renunciar a las regulaciones ambientales y al hacer la vista gorda ante transacciones inmobiliarias dudosas. Pero en verdad el PT estaba 


\section{Salvador, Bahia}

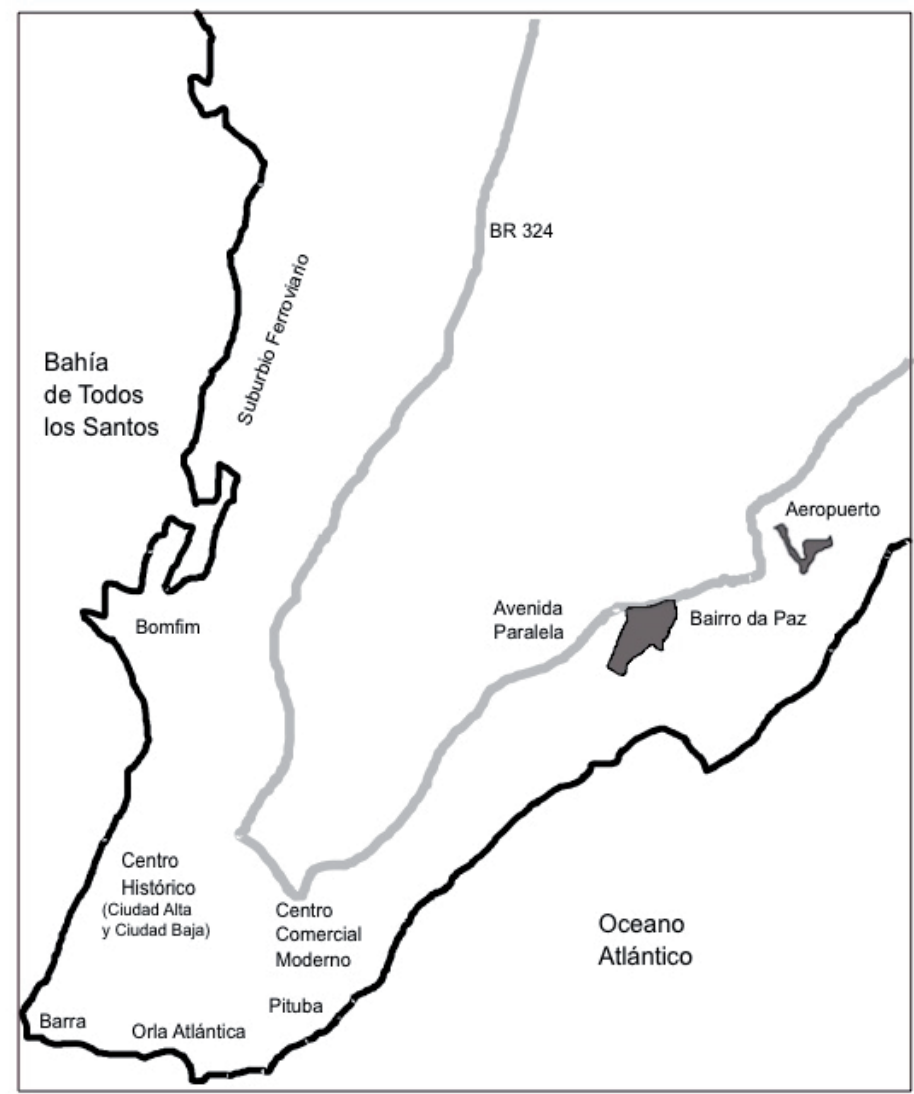

tan en deuda con empresas inmobiliarias y de la construcción por el financiamiento de la campaña como cualquiera de sus partidos oponentes. Esto, naturalmente, aumentó la ansiedad de los residentes del Bairro da Paz sobre su futuro y el de las inversiones realizadas en las casas y negocios.

El Bairro da Paz nació en la violencia, en tanto los planes de modernización de Salvador de Antônio Carlos Magalhães implicaron un fuerte elemento de "limpieza social" y desposesión de las familias negras pobres de las zonas donde su presencia impedía la construcción de nuevas carreteras así como la colonización del espacio por familias de clase media y alta. La perseverante resistencia a las acciones violentas de la policía permitió a la comunidad sobrevivir hasta un breve período más tolerante del gobierno del estado, que acabó con la amenaza de desalojo inmediato, y lentamente el barrio comenzó a acumular infraestructura y servicios - en su mayoría instalados por organizaciones no gubernamentales - , junto con algunos pequeños negocios. Sin embargo, en 1992 los propietarios de esos negocios 
contrataron una milicia para "limpiar" el barrio de los "indeseables". Como Mónica Silva Nunes y Jairnilson Paim (2005) han demostrado, esto se ajusta a un patrón común. En las comunidades pobres y estigmatizadas territorialmente, la limpieza de los "bandidos" por parte de escuadrones de exterminio - generalmente formados por agentes fuera de servicio o retirados de la policía - podría evocar sentimientos ambiguos por parte de los residentes cuando se trata de la muerte de individuos específicos, pero como ocurría previamente al nuevo orden del PCC en São Paulo, el linchamiento y otras prácticas de "autodefensa" eran generalmente aceptadas en un contexto en el que poco se esperaba del Estado, excepto autoritarismo y malos tratos. En el caso estudiado por estos autores, las tasas de homicidio se redujeron después de la primera "limpieza", pero cuando empezaron a aumentar de nuevo en la segunda mitad de la década de 1990, los residentes no parecieron registrar subjetivamente este cambio. Nunes y Paim sugieren dos explicaciones, no excluyentes entre sí: en primer lugar, que ciertos tipos de violencia, incluida la violencia policial contra los jóvenes considerados "marginales" por su participación en el tráfico de drogas, ahora se ha convertido en "aceptada" como "normal", y en segundo lugar, que el control más fuerte ejercido ahora sobre el barrio por el capo local del narcotráfico inhibía las expresiones de insatisfacción con el "orden del crimen" que éste había impuesto en la comunidad. No obstante, mi propio material etnográfico me lleva por un camino algo más complicado.

Siguiendo el patrón de Río de Janeiro, la milicia escapó pronto del control de las personas que la llevaron al barrio, y comenzó a extorsionar a cambio de protección a todo el mundo. Tratándose de personas que habían sido obligadas a autoorganizarse mejor que la mayoría, simplemente para evitar ser desalojados, los líderes de Bairro da Paz lograron crear suficiente turbulencia política y mediática para conseguir que la milicia se disolviera y se encarcelará a algunos de sus miembros. Las autoridades respondieron a las demandas de mejora de la seguridad de la comunidad mediante la instalación de un puesto de policía, pero resultó un fracaso devastador. Me encontré con un notable acuerdo entre los residentes de ambos sexos y de diferentes edades, niveles educativos, ocupaciones, credos y tendencias políticas, en cuanto a que los agentes en el cargo eran inaceptablemente autoritarios y racistas. La gente más joven relató interminables historias de detenciones y registros sin razón, hablando de agresiones físicas así como de maltrato verbal. Tales prácticas abusivas a menudo eran explícitamente racistas, a pesar del hecho de que la policía militar esté en sí misma compuesta a menudo por afro-descendientes que viven en tipos similares de barrios periféricos: una de las mujeres policías que prestó servicio en una Base Comunitaria de Seguridad [Base Comunitária de Segurança] comentó que deseó que instalaran una donde ella vivía. Hay varias maneras de ver esta aparente paradoja. La cultura dominante de la policía militar — a menudo criticada por los nuevos policías - es autoritaria, las comunidades vigiladas están estigmatizados como nidos de criminales violentos y la policía por lo general no tiene capacitación en Inteligencia para identificar quién podría ser peligroso o no. Esta situación es aún peor cuando la base policial se encuentra fuera de las comunidades y simplemente entra en ellas para participar en una "ostensible" vigilancia o a la caza de "sospechosos": es mejor 
tratarlos a todos como "sospechosos". Pero a veces los propios residentes identifican a vecinos o a sus hijos como "marginales", siguiendo la lógica de una sociedad desigual que obliga a todos "los de abajo" a participar en una lucha diaria por afirmar su cualidad de "persona" (Linger, 1992), aunque sea a expensas de los demás. La policía militar se encuentra enredada en la misma lógica, pero sus reacciones se acentúan por los peligros reales de muerte o lesión con los que se enfrentan en su trabajo, dentro o fuera de servicio ${ }^{26}$, y por la incorporación de un discurso securitario que exagera la criminalidad de todos los pobres - y que, por lo tanto, puede ayudar a convencer a algunos, entre ellos algunos policías, de que su exterminio es legítimo- . Todo ello refuerza el "ennegrecimiento" de la pobreza, tan característico de Brasil.

El puesto de policía fue finalmente reemplazado por patrullas móviles cuyas visitas eran poco frecuentes y generalmente se centraban en la caza de conocidos narcotraficantes. Cuando comencé a visitar Bairro da Paz en 2006, el puesto estaba aun operativo y los residentes se quejaban por la necesidad de formar guardianes del orden público más civilizados y menos corruptos. Sin embargo, después de que el puesto fuera retirado, la gente empezó a decir que en ese momento estaban muy contentos con su seguridad, y me decían — verosímilmente- que era mucho más seguro caminar por las calles de Bairro da Paz en las primeras horas de la madrugada - como los jóvenes de clase media harían cuando llegan a comprar drogas - que en los barrios de lujo bahianos donde las clase media y alta vive defensivamente en el interior de condominios cerrados. Lo que sucedía era que el líder del narcotráfico en el Bairro da Paz instituyó el modelo de PCC e impuso "el orden del crimen" en la comunidad. Los servicios del grupo incluyen la mediación en disputas personales y entre familias, y aunque los que persistentemente rompen las nuevas reglas contra el robo de otros miembros de la comunidad pueden esperar un severo castigo hecho público, la comunidad realmente se convirtió en un lugar "tranquilo" y las operaciones de tráfico de drogas se volvieron muy discretas, sin ostentación pública de armas. Mis entrevistas con los residentes no revelaron un patrón uniforme de entusiasmo positivo por la "ley del crimen", aunque algunos lo juzgaron preferible a la policía oficial y a los sistemas judiciales. Algunos, sobre todo los jóvenes que habían entrado en el mundo del tráfico, eran firmes partidarios, pero los que fueron más críticos con la situación a menudo sugirieron que el miedo era la razón por la que los demás no decían nada. Sin obstante, incluso aquellos que expresaron su absoluta consternación por el hecho de que el abandono estatal los dejó abocados a ser gobernados por criminales, expresaron escasa satisfacción con la alternativa del estado, generalmente basándose en experiencias personales profundamente frustrantes.

Aunque a principios de 2011 algunas personas supieron que algo semejante al modelo de las UPP de Río estaba previsto para Bahía, y que Bairro da Paz estaba en la lista de las comunidades programadas para recibir una Base Comunitária, la

${ }^{26}$ Por ejemplo, los policías fuera de servicio, identificados por ladrones armados de autobuses de pasajeros, bien pueden ser asesinados, incluso si no reaccionan al asalto. 
idea inicialmente provocó poco entusiasmo. Esto refleja el escepticismo sobre la posibilidad de crear un tipo de policía más "civilizada", incluso más, el escepticismo sobre si las prometidas y tan necesarias nuevas inversiones en infraestructura y programas de desarrollo social serían cumplidas en realidad, la ansiedad acerca de si la intensificación de la vigilancia de la comunidad podría en realidad formar parte de una estrategia para disminuir su capacidad para resistir al desplazamiento, o en definitiva simplemente ser un medio para mantener contentos sobre su seguridad a los residentes de clase media de los condominios circundantes, a costa de la humillación e inconvenientes causados a los residentes. Una de las cosas que llamó la atención de la gente sobre las UPP bahianas, fue el uso de las tecnologías de vigilancia basadas en sistemas de circuito cerrado de televisión. Teniendo en cuenta que las calles no eran realmente peligrosas en aquel entonces, esto pareció una provocación.

Pero el año 2011 fue el que trajo cambios transcendentales. En abril, la compañía que edificaba los condominios junto al Bairro da Paz, envió a sus agentes de seguridad privada para desalojar a un grupo de familias que había construido chabolas en la linde, con el argumento de que estaban en propiedad de la empresa. En septiembre estalló un nuevo conflicto en relación a un pedazo de tierra en la que los residentes de Bairro da Paz tenían la esperanza de construir un centro deportivo con fondos de la PAC, cuya titularidad se disputó entre dos especuladores de suelo urbano. Guardias armados acudieron a proteger a los trabajadores que limpiaban el terreno produciéndose un enfrentamiento con los residentes que objetaban que se estaban violando las leyes medioambientales. Más allá de la violenta confrontación que se produjo en enero de 2012, pero poco después de este incidente, uno de los dos empresarios que reclamaba la titularidad de las tierras, el señor Cintra, cayó en una trampa y murió a tiros en su coche junto su hijo, un estudiante, frente al terreno de la disputa. Cintra había acordado, un año antes en una reunión, donar el terreno a la comunidad para el centro deportivo. El crimen se produjo delante de la puerta del jefe de los guardias de seguridad que había intimidado a los residentes, a los que la víctima había denunciado anteriormente por amenaza de muerte. Posteriormente se supo que Cintra había estado pasando información a la oficina de la fiscalía sobre las ilegalidades en la escrituración de las tierras en las que sus rivales estaban construyendo ${ }^{27}$. Aquí, entonces, los residentes de Bairro da Paz y sus dirigentes parecen tener una espantosa muestra de los extremos a los cuales los promotores inmobiliarios pueden llegar para defender sus intereses. Pero dado que agentes fuera de servicio y policías retirados estaban implicados en la violencia, constituye también otro caso paradigmático de la forma en que el poder público puede ser apropiado por intereses privados. El incidente intensificó los sentimientos de inseguridad, pero en el sentido de incrementar la desconfianza en el estado. El empresario asesinado fue atraído hacia su muerte por lo que parecía ser un cartel oficial municipal erigido en las tierras de la disputa, que posteriormente fue declarado falso por la prefectura. Sin embargo, los acontecimientos fueron minando, simultáneamente, el "orden del crimen" paralelo en el Bairro da Paz. El traficante que había establecido el modelo

27 “Cintra interpone queja por amenaza contra Osmar”, Jornal A Tarde, $1^{\circ}$ de febrero, 2012. 
de PCC en el Bairro da Paz estaba ahora en prisión, aunque esto como ya hemos visto, no constituyera necesariamente un impedimento para continuar al mando de la comunidad. Pero en septiembre de 2011, una mujer amiga que lo visitó en la cárcel y que trabajaba como limpiadora en un centro comercial cercano, fue ejecutada salvajemente con treinta balazos que impactaron en su cuerpo, diez de los cuales fueron dirigidos, con una evidente carga simbólica, a su boca. Se desarrolló una lucha por el control del tráfico en el Bairro da Paz, que finalmente llevó a una invasión armada, la quema de algunas casas y saqueos, que los medios de comunicación atribuyeron a los traficantes rivales del asentamiento cercano del Alto de Coqueirinho. Al día siguiente, un extraño silencio se cernía sobre las principales calles, normalmente bulliciosas incluso en la tarde. El Bairro da Paz había dejado de ser un lugar pacífico. Y una vez más, el desempeño de la seguridad del estado fue pésimo. La policía y los bomberos tardaron cuarenta minutos en responder a las llamadas de emergencia de los residentes.

Finalmente, un año más tarde el Bairro da Paz recibió una Base Comunitaria de Segurança, pero pocos líderes comunitarios se dejaron ver en la ceremonia de apertura en la que el gobernador Wagner y el secretario Barbosa fueron agasajados con música afro y una exhibición de capoeira. El edificio de la base aún no estaba listo, así que fue situado provisionalmente en un edificio en la periferia de la comunidad y el joven comandante no tenía ninguna agente mujer bajo su mando, en contradicción sorprendente con el modelo de mejores prácticas de las BCS, que reconocía la importancia del trabajo conjunto de hombres y mujeres cuando se trata de edificar relaciones más constructivas con la población en las calles y, en particular, cuando entran en los hogares en los que las mujeres y los niños pueden estar sin la compañía de hombres.

La agresiva manera en que la policía invadió hogares en busca de drogas, armas y sospechosos en la primera ocupación, provocó quejas que continuaron en los primeros meses de existencia de la base, acompañadas de acusaciones de daños a la propiedad y de intimidación de menores de edad en las operaciones de inteligencia. Aunque un número importante de residentes ya estaba dispuesto a dar la bienvenida tácitamente a la presencia policial porque prometía el fin permanente a la guerra de la droga, la policía no emprendió las patrullas regulares de a pie en las calles, que son tan esenciales para la construcción de relaciones positivas con los residentes a través de interacciones habituales y para superar su escepticismo acerca de la posibilidad de nuevos estilos de actuación policial. Las patrullas motorizadas de la base no se aventuraron muy frecuentemente dentro de la mitad superior de la comunidad. Todo esto podría reflejar, simplemente, la manera en que se ha conducido la política bahiana según sus conveniencias sin una inversión suficientemente sólida para la formación y preparación, pero también podría reflejar que el hacer la vida más segura para los residentes no es una prioridad en la política de seguridad pública de Bahía.

Aunque los agentes de la policía militar hablaron con algunos líderes de la comunidad del Bairro da Paz antes de establecer la base, no se intentó involucrar a la comunidad en su conjunto en este proyecto. La consulta fue más notoria en el caso del Nordeste de Amaralina el año anterior, y tal vez el hecho de que los traficantes 
asesinaran a un sacerdote Candomblé, que se pronunció a favor de la base en una de las reuniones públicas preparatorias, promovió una aproximación diferente en otro sitio. Pero puede que haya lecciones para el Bairro da Paz a partir de la experiencia en el Nordeste de Amaralina. A pesar de la instalación de las tres BCS, el tráfico de drogas no concluyó en el complejo del Nordeste de Amaralina, y trabajar con los nuevos señores de la droga locales emergentes, se mantuvo como una fuente de prestigio para quienes tomaron dicha opción. Durante el año posterior a la instalación de la BCS, el tráfico en la zona de Boqueirão pasó a manos de una facción que se había separado del Comando da Paz, con la cual está asociado el grupo de traficantes que actualmente domina el Bairro da Paz. El último presunto narcotraficante del Nordeste en ser arrestado, Leandro Marques Cerqueira de 32 años, fue detenido por la policía a finales de noviembre de 2012 mientras se preparaba para salir hacia São Paulo con 39.500 reales en efectivo, siguiendo el arresto días antes de Marcelo Henrique - también conocido como "Elías"-, otro supuesto líder al que se distingue por ser el "As de Diamantes" en la "baraja del crimen" de la Secretaría de Seguridad Pública (SSP) ${ }^{28}$. Leandro, quien estuvo en prisión en 2006 por haber participado en un homicidio, aseguró que hacía tiempo que había dejado atrás el narcotráfico y que todo lo que tenía reflejaba un sólido trabajo como taxista. Tal vez ésta no era la tapadera ideal a escoger en aquel momento, ya que la policía acababa de detener a otro taxista de 32 años de otra parte de la ciudad, Elio de Jesús Matos, junto con su novia, por liderar una banda de mayoristas de venta de cocaína. A través de una red de contactos, compraban las drogas que llegaban por carretera ocultas en camiones comunes de carga desde São Paulo, para su posterior reventa a los capos de la comunidad ${ }^{29}$. Aunque Elio presuntamente organizaba suntuosas fiestas para sus amigos, traficantes muchos de ellos, y le gustaba hacer viajes junto con éstos en goleta alrededor de la Bahía de Todos los Santos, proporcionando prostitutas en abundancia para su entretenimiento, los compañeros de su parada de taxis expresaron asombro al enterarse de su detención, ya que al parecer pasaba largas horas al volante de su taxi ${ }^{30}$.

Esas detenciones obtuvieron la publicidad suficiente y permitieron a las autoridades proyectar una imagen de una exitosa campaña contra el "crimen organizado". Sin embargo, el historial de las BCS de Nordeste se mantuvo muy desigual. La violencia continuó ocurriendo en las inmediaciones de uno de ellos: un conserje

28 "Líder del tráfico de Boqueirão está preso", Correio da Bahia, 27 de noviembre, 2012. "Policía coge al gerente del tráfico en el Nordeste de Amaralina", Correio da Bahia, 21 de noviembre, 2012.

${ }^{29}$ Los circuitos y las conexiones entre las zonas de producción, transporte, procesamiento, distribución y consumidores en el mercado de drogas en Brasil, son muy complejos e involucran una multitud de actores, muchos de los cuales disimulan su implicación detrás de otras actividades. Aunque no hay equivalentes a los carteles mexicanos, existe organizaciones criminales transnacionales de base familiar que controlan la producción y el cargamento de drogas a lo largo de las fronteras de Paraguay y Bolivia y generalmente son propietarias de de haciendas a ambos lados de las fronteras. Estas fronteras son de tal extensión que hacen extremadamente difícil su vigilancia efectiva.

30 "Cae un mayorista de polvo" [NT, cocaína] Correio da Bahia, 24 de noviembre, 2012. 
de escuela fue asesinado. Los residentes informaron que la policía no salía de la base a patrullar regularmente, reduciendo así al mínimo su posible contribución a garantizar la seguridad de la gente de a pie, y señalaron que podrían estar recibiendo muy poca información al permanecer en el interior de su edificio ya que todas las cámaras de seguridad que el barrio tenía habían sido destruidas por los chavales que trabajaban como vigías de los traficantes. Muchos residentes de Bairo da Paz probablemente estarían de acuerdo con la descripción hecha por un residente de Nordeste de Amaralina sobre del funcionamiento de su base de policía local:

La policía de la $\mathrm{UPP}^{31}$ (sic) sólo es buena para golpear a los padres de familia y calificar a respetables madres de vagabundas... lo que necesitamos aquí es más seguridad, pero la policía simplemente pasa el rato alrededor de la entrada de su base para exhibirse ante las chicas jóvenes en lugar de velar por la seguridad de la gente.

Es tentador llegar a la conclusión que debido a que las detenciones de los traficantes componen buenos titulares, esto se ha convertido en parte central de la política Bahiana, a pesar de que no conlleve un gran cambio en la vida de los residentes de las comunidades, si nuevos traficantes toman el relevo en ellas. En junio de 2012, meses antes de la "pacificación", la policía detuvo a tres miembros de una de las facciones cuya lucha por el control del tráfico en el Bairro da Paz había provocado el estallido de la violencia el año anterior, y su principal líder, alias "Flor", huyó. Sin embargo, traficantes de otros lugares entraron en la comunidad, incluso después de que la BCS se hubo instalado. Hacia finales de 2012 el resurgimiento de una facción del Comando da Paz no sólo controlaba Bairro da Paz, sino también las comunidades vecinas. Según el curso habitual de los acontecimientos, dicho desarrollo hubiera disminuido la violencia relacionada con la competencia por el control de territorios locales.

En este punto vale la pena volver a enfatizar que Bahía presenta el mismo tipo de fragmentación que Río dentro del mundo del narcotráfico. Una de las consecuencias de esta fragmentación es la violencia relacionada con los intentos de hacerse cargo de la distribución de la droga en una localidad en particular, produciendo ciclos en los que las fases de tranquilidad y estabilidad, en el que una banda local en particular puede alcanzar un modus vivendi razonable con los residentes y también con la policía corruptible, pueden de repente convertirse en escenas de violencia y caos antes de que el conflicto se resuelva con la victoria de los defensores o invasores. Este ha sido un problema que viene de lejos en las favelas de Río de Janeiro (Misse, 1997), y uno que acabamos de ver ejemplificado por el Bairro da Paz de Bahía. Sin embargo, es interesante reflexionar sobre si la violencia no puede a veces verse exacerbada por el desplazamiento de los narcotraficantes resultante de la instalación de una UPP/BCS. El Secretario de Seguridad Pública, Maurício Teles Barbosa, aceptó de hecho esta hipótesis en una entrevista con el periódico Correio da Bahia, ofrecida en el momento en que la base de Barrio da Paz estaba instalándose. Éste argumentó

${ }^{31}$ Aunque yo haya utilizado el término oficial, muchos bahianos se refieren a las BCS como UPP, en la medida en que saben que el modelo procede de Río. 
que el desplazamiento de los traficantes se había tenido en cuenta en la planificación estratégica al decidir dónde ubicar las BCS, la cuál se basaba en la "inteligencia" - aunque también dijo que era demasiado pronto para decir donde "Flor" podría haber buscado refugio-. Para el secretario y jefe de policía coordinador del programa de BCS, Coronel Zeliomar Almeida, también titular del departamento de "prevención de la violencia" de la SSP, la instalación de las UPP producen inevitablemente un aumento de la violencia en las zonas donde los traficantes migran. $\mathrm{La}$ alternativa de que los traficantes encuentren simplemente un refugio seguro en otro lugar donde tienen familiares o amigos de la misma facción, no se consideró en este análisis. Su premisa tácita era que los traficantes generalmente han establecido una base social en las comunidades que dominaron antes de huir, si no es a través de una exitosa administración de la "ley del crimen", al menos mediante varios tipos de patrocinio, tales como la compra de medicamentos para enfermos, financiando eventos de la comunidad, o distribuyendo regalos a los niños en Navidad. La SSP llega a la conclusión de que crear una clientela por medios pacíficos lleva tiempo, y por ello una vez desplazados los traficantes se verán seriamente debilitados, a pesar de que tengan dinero. Reducidos a la desesperación, los traficantes expulsados de sus territorios, utilizarán tanta violencia como puedan reunir para establecer el control sobre una nueva zona, y en tanto los traficantes locales normalmente se resisten, la lógica implícita en el análisis es que los bandidos harán el trabajo de la policía más fácil, matándose unos a otros ${ }^{32}$.

Aunque esto no podría ser descrito como una "política" formal, debe reconocerse al aparato de seguridad pública de Bahía el hacer relativamente explícito este tipo de pensamiento. Sin embargo, puesto que rara vez sólo son los "bandidos" los que mueren por las balas perdidas que sobrevuelan las violentas luchas por el control de los territorios de distribución del narcotráfico, esta transparencia sólo incrementa la sospecha de que la seguridad y el bienestar de los residentes de la comunidad es una prioridad secundaria, y posiblemente no es una prioridad en absoluto, de una política impulsada por el deseo de sumar "victorias" en la lucha contra el tráfico de drogas. Ya sabemos, sobre la base de décadas de experiencia, que encarcelar o incluso matar a generaciones enteras de capos a nivel comunitario no ha tenido el menor efecto en el crecimiento continuo del tráfico de drogas y de la adicción en Brasil, que ofrece actualmente el mayor mercado del mundo de pasta base de cocaína [crack] y el segundo más grande en el consumo de cocaína en general, según un estudio de la Universidad Federal de São Paulo ${ }^{33}$. Desde este punto de vista, puede que haya mejores perspectivas de reducción en el consumo de crack si la oferta se reduce como consecuencia de la necesidad de los traficantes, que se quedan "fijados" en sus comunidades, de negociar sus relaciones con los residentes y manifestar algún tipo de conciencia social. A mediados de 2012, los capos del narcotráfico de las favelas

32 "Los traficantes que huyen de las bases de la Polícia buscan actuar en otros barrios", Correio da Bahia, 15 de Septiembre, 2012.

33 "Boom del crack de cocaína de Brasil", Financial Times, Beyondbrics blog, http://blogs. ft.com/beyond-brics/2012/09/11/brazils-crack-cocaine-boom/\#axzz265Rd7RKy, acceso 11 de septiembre de 2011. 
Mandela y Jacarezinho de Río de Janeiro, tomaron la decisión de prohibir la venta de crack en sus comunidades. La lectura oficial fue que se trataba de un movimiento defensivo en respuesta a la ofensiva de la seguridad pública, que incluyó acciones contra las cracolândias en las cuales las autoridades de la ciudad buscaron formas de legalizar el internamiento obligatorio de los adictos. Estas favelas habían sido ya elegidas para la pacificación ${ }^{34}$. Pero los traficantes insistieron en que la decisión era suya, un reflejo de su preocupación por la forma en la que el crack estaba acelerando la desintegración social de las comunidades en las que muchos de ellos habían nacido y crecido $^{35}$. Los señores de la droga brasileños son tan capaces de ser "políticos", como los policías y los políticos profesionales. Sin embargo, ya que parece poco probable que haciendo redadas de adictos y encerrándolos en una clínica en contra de su voluntad pueda resolver los problemas de salud pública que el crack causa, esta es otra razón para pensar acerca de las consecuencias no deseadas de las políticas que promueven la migración de los criminales violentos a zonas en los que no tienen lazos sociales con la población local.

La encarcelación de los señores de la droga, como hemos visto, no necesariamente acaba con su control del narcotráfico local, ya que a menudo pueden seguir comandándolo desde la cárcel, pero esto también es una cuestión del tipo de relaciones sociales que ellos y sus asociados pueden continuar cultivando en sus comunidades. Si la vigilancia introducida por las UPP y BCS no incluye una ruptura radical con los patrones del pasado, es improbable que el Estado vaya a tener éxito en quebrar el poder de los traficantes. Incluso si una vigilancia agresiva o corrupta que aparta a los residentes del estado es fuertemente sancionada, a menos que el entorno social en el que el tráfico y el consumo de drogas tiene lugar puede cambiarse, sacar a los líderes existentes o incluso a las bandas al completo, no prevendrá de otros que desean asumir el control de estos mercados lucrativos ilegales. Incluso podría merecer la pena pensar si una política de "represión condicional" podría ser ampliada para ofrecer a los traficantes existentes, otras alternativas que no sean el desplazamiento o el encarcelamiento.

\section{Conclusión: lecciones de la Bahía}

En Bahía, hasta la fecha sólo el pequeño proyecto inicial de una BCS en Calabar ha producido una clara evidencia de aprobación general por parte de los residentes. Las agentes, que eran voluntarias y estaban fuertemente comprometidas con el proyecto, tuvieron una participación destacada en la "pacificación" de Calabar, bajo el mando de una mujer comandante. La apelación a una "naturaleza" femenina esencializada para justificar el incremento de su presencia en las unidades policiales de la comunidad, es evidentemente debatible: en Bahía las mujeres pueden liderar

34 "El narcotráfico pone carteles en Jacarezinho prohibiendo la venta de crack en la favela", http://g1.globo.com/rio-de-janeiro/noticia/2012/06/trafico-fixa-cartazes-no-jacarezinhoproibindo-venda-de-crack-na-favela.html, acceso 20 de junio, 2012.

35 "Traficantes de drogas de Brasil proscriben el Crack: traficantes de favelas dicen las drogas 'desestabilizan' las comunidades”. http://www.huffingtonpost.com/2012/08/22/brazil-drugdealers-ban-crack_n_1822870.html, acceso 22de agosto, 2012. 
bandas de narcotráfico y participar en crímenes extremadamente violentos. Pero el fracaso en mantener una política de inclusión de más mujeres en la policía comunitaria, y en proporcionar la capacitación especial prometida a todos los agentes desplegados en las BCS, ha sido reconocido como un problema por los agentes que prestan servicios en algunas de las unidades más recientemente formadas, la mayoría de los cuales fueron reclutados en el programa en lugar de voluntarios. Como destacó un policía militar entrevistado, con impresionante candor, él sólo había sido entrenado para ser eficaz en la "represión policial" y simplemente no sabía cómo crear un modo diferente de relación con la gente en la calle. Este es un ejemplo de los problemas causados a la policía, tanto como a los ciudadanos menos favorecidos, por la improvisada y politizada naturaleza de la "UPP bahiana".

Un modo equivocado de vigilancia policial fácilmente socavaría las posibilidades de ganar el apoyo comunitario para las bases. En el caso de Bairro da Paz, el miedo a los traficantes inhibió el avance de expresiones públicas de apoyo al proyecto entre los residentes y líderes de la comunidad por igual, a pesar de que mucha gente estaba dispuesta a admitir en privado que pensaban que una "UPP" ahora era la mejor opción, dado el número de asesinatos que el trastorno de la "ley del crimen" estaba provocando. Por desgracia, los primeros meses de la "pacificación" no se construyeron sobre esa base potencial para ganar los corazones y las mentes con tanto éxito como podría haberlo hecho.

Aun cuando menos exitosas, generalmente las UPP reducen las tasas de homicidio, y aunque parezcan menos capaces de eliminar el tráfico por completo, éstos podrían poco a poco alentar cambios en el modo en que las drogas son distribuidas, lejos de los modelos basados en el control armado de un territorio, y tal vez incluso reduciendo el suministro de las drogas que causan mayor daño en la salud y la capacidad de funcionar en la sociedad. Las opiniones en Bairro da Paz podrían llegar a ser más positivas si las mejoras tan necesarias en infraestructura y servicios se ejecutan junto con el nuevo régimen de seguridad. Las actitudes también podrían cambiar si se les pudiese dar seguridad a los residentes sobre la tenencia, o garantías de que no serán desplazados por razones tendenciosamente clasistas de "interés público", incluso sin considerar las "alternativas sostenibles" al desalojo o la oferta de realojamiento de Raquel Rolnik, que representarían un movimiento hacia adelante en sus vidas, antes que hacia atrás.

No está claro si existe una voluntad política para pensar en tales medidas, incluso por parte del PT y sus aliados, derrotados por la derecha en las elecciones municipales de 2012 y temerosos ahora de perder el control del gobierno estatal en 2014. Sin embargo, está claro que las políticas públicas de seguridad requieren ser democratizadas, de modo que las personas a las que pueden aplicarse en sus formas más represivas sientan que han participado en el establecimiento de prioridades, prioridades que son significativas para ellos en términos de sus experiencias particulares de inseguridad económica, social y física. Ellos también necesitan sentir que las autoridades comprenden sus problemas inmediatos de cada día y sus aspiraciones y deseos a largo plazo. Existen mecanismos institucionales para ello, como las Audiencias Públicas que las organizaciones comunitarias en Bairro da Paz han 
convocado para dialogar con las autoridades públicas, y los Consejos de Seguridad Comunitarios (Conselhos Comunitarios de Segurança, CONSEG), los cuales se supone que deben reunir a la policía y a los representantes de los diferentes tipos de residentes que habitan en una región. Pero aunque los representantes de Bairro da Paz han participado en el CONSEG local, siempre ha resultado difícil trascender las barreras de la desconfianza que dividen al Bairro da Paz de los residentes de clase media de los condominios circundantes, dada especialmente la tendencia de los agentes superiores de la policía a identificar Bairro da Paz con el hogar de atracadores y ladrones de la zona, así como de los narcotraficantes. Las percepciones negativas pueden ser reforzadas en el corto plazo por la instalación de una BCS a menos que se tomen medidas activas para cambiar la comprensión en diferentes direcciones. Sin embargo, como están las cosas, el gobierno puede preferir centrarse en convencer a la gente de clase media que las BCS les van a garantizar, en lugar de a los residentes de los barrios pobres, un mejor nivel de "seguridad ciudadana".

No obstante también hemos visto que incluso las aspiraciones más limitadas para las BCS no se cumplirán a menos que la naturaleza de la vigilancia policial cambie. Hacer esto no dependerá simplemente de una mejor formación y de la firme aplicación de las sanciones para reducir el autoritarismo, el incumplimiento del respeto a los derechos humanos y la corrupción. También se requerirán mejoras en la remuneración, y en las estructuras de la carrera profesional, que harían disminuir la actual "captura" de los agentes del poder público por parte de intereses privados.

Las dificultades para conseguir una reforma radical de la policía se pusieron en evidencia en la huelga, en febrero de 2012, llevada a cabo por miembros de la policía militar de Bahía afiliados a la ASPRA (Asociación de Policía, Bomberos y sus Familias del Estado de Bahia/ Associação dos Policiais, Bombeiros e tareas pendientes Familiares seus do Estado da Bahia). Los huelguistas adoptaron tácticas muy similares a las adoptadas por las organizaciones del crimen: quemaron autobuses y coches patrulla, y crearon un "rumor central" que extendió desinformación y temor por toda la ciudad. Escuchas telefónicas revelaron una planificación conjunta con los colegas de Río de Janeiro y agendas políticas comunes. Entre ellas se encontraba la grabación de una mujer policía tratando de organizar la invasión armada de un puesto policial ocupado por agentes que no estaban haciendo huelga ${ }^{36}$. Ya que muchas otras acciones realizadas durante la huelga fueron ilegales — las huelgas de la policía militar son técnicamente motines-, cuando terminó, el gobierno del estado envió a algunos de sus cabecillas a la cárcel. Sin embargo, el principal dirigente resurgió al presentarse como candidato a concejal en las elecciones municipales por el PSDB, y como "Soldado Prisco" consiguió la cuarta votación más alta de los 69 candidatos electos. Aunque se enviaron tropas federales para asegurar la ciudad y

${ }^{36}$ El caso personal ofrece una trágica demostración de la necesidad de evitar presupuestos acerca de la naturaleza femenina en el trabajo policial. Esta joven mujer se unió a la policía para satisfacer sus ambiciones de estilo de vida, centrados en la posesión de una poderosa moto. Un accidente con la moto la dejaron con permanentes dolores, dependiente de medicinas que consumían todo su salario. "PM sufiría perturbaciones, alega defensor", Jornal A Tarde, 14 de febrero, 2012. 
proteger el edificio estatal del parlamento, que los huelguistas habían ocupado y destrozado, imitando la huelga de bomberos de Río de Janeiro, tanto ellos como los colegas no huelguistas de la policía militar y civil hicieron poco esfuerzo para ocultar su simpatía por los huelguistas. En un primer nivel, esto parece totalmente razonable, ya que el gobernador Wagner siguió un mismo patrón en todo el país, al no cumplir plenamente con los aumentos salariales acordados y las mejoras en la estructura de la carrera profesional, y fue también fulminante acerca de la ilegalidad del "motín" a pesar de haber apoyado plenamente una huelga previa de la policía antes de que su carrera cambiara del sindicalismo a la política electoral. Pero el gobernador no estaba del todo equivocado al centrarse en las ilegalidades. Durante los doce días de la huelga se cometieron 135 asesinatos. De entre ellos, el Departamento de Homicidios y Protección de la Persona detectó 45 casos que manifestaban "características de exterminio". Entre aquellos, el director del departamento sospechó que en torno a 25 ó 30 asesinatos fueron probablemente cometidos por policías que actuaban como milicias clandestinas o agentes de seguridad privados pagados por los encargados de tiendas de las comunidades pobres, dado que al mismo tiempo que los autores estaban enmascarados, utilizaron armas restringidas de uso militar ${ }^{37}$. Esta no es la única evidencia disponible sobre la larga y continua importancia de los escuadrones de la muerte en Bahía. Ante las frecuentes protestas públicas de los familiares de las víctimas, el gobierno estatal creó un departamento especial de la policía para hacer frente al problema, a pesar de que sólo tuvo éxito en lograr la condena de tres de las más de 300 personas contra las cuales se habían emitido acusaciones entre 2004 y 2007, cuando fue sometido a un severo recorte de personal (Noronha, 2008).

Los brasileños de clase trabajadora no se oponen necesariamente a la exterminación de los "marginados" y los "bandidos" (Caldeira, 2002), mientras que la "ley del crimen" en sí misma no se caracteriza por su voluntad de garantizar los derechos humanos a los violadores. Es importante no idealizar ninguno de los actores en los complicados escenarios en los que la política de seguridad esta involucrada - $\mathrm{O}$ indebidamente demonizarlos, ya que los mayores criminales de todos, no viven en las favelas-. En la exploración de las contradicciones, las consecuencias no deseadas y posibles agendas ocultas de las políticas de seguridad pública, tenemos que tratar de ver a través del humo creado por la securitización de la pobreza para captar las realidades sociales y relaciones de poder que dan forma al modo en que tales políticas son implementadas y se ponen en práctica, las realidades y las relaciones que aún están dentro de nuestra esfera de comprensión, para hacer transformaciones permanentes a través de otros tipos de acción pública.

Traducción: Alvar Gallardo de la Torre Revisión: Adela Franzé Mudanó

${ }^{37}$ Journal A Tarde, 15 de febrero, 2012. 


\section{Referencias bibliográficas}

ARIAS, Enrique Desmond

2006 Drugs \& Democracy in Rio de Janeiro: Trafficking, Social Networks, and Public Security. Chapel Hill: UNC Press Books.

CALDEIRA, Teresa P.R.

2002 "The paradox of police violence in democratic Brazil", Ethnography 3(3): 235-63.

CARAMANTE, André and Afonso BENITES

2012 "Corregedoria suspeita que policiais venderam dados de PMs a bandidos", Folha de São Paulo, 13 de noviembre, 2012.

CEPAL

2012 Panorama social de América Latina 2012. Santiago de Chile: Comisión Económica para América Latina y el Caribe.

CUNHA, Neiva Vieira

2012 "Vivienda popular y seguridad pública: el proceso de 'pacificación' en las favelas de Río de Janeiro". In Dimensiones del habitat popular latinoamericano, Teolinda Bolivar y Jaime Erazo Espinosa (Eds.). Quito: FLACSO, CLACSO e Instituto de la Ciudad.

DE SOUZA, Luís Antônio Francisco, Thaise MARCHIORI, Naiara CONSERVANI SCHMIDT, y Douglas GUIMARÃES SILVA

2009 "Políticas locais de segurança pública". In Políticas se segurança pública no estado de São Paulo: situação e perspectivas a partir das pesquisas de observatório de segurança pública da UNESP, edited by Luís Antônio Francisco DE SOUZA. São Paulo: Cultura Acadêmica, Editora UNESP.

DRUCK, Graça

2011 “Trabalho, precarização e resistências: novos e velhos desafios?” Caderno CRH 24 (número especial 1): 35-55.

FELTRAN, Gabriel de Santis

2010a "The Management of Violence on the São Paulo Periphery: The Repertoire of Normative Apparatus in the PCC era", Vibrant 7(2):109-134.

2010 b "Crime e castigo na cidade: os repertórios da justiça e a questão do homicídio nas periferias de São Paulo”, Caderno CRH 23(58): 59-73.

GAIO, André Moysés

2006 “O estado delinqüente: uma nova modalidade de crime?" Cadernos de Ciências Humanas - Especiaria 9(15): 137-157.

HANDZIC, Kenan

2010 "Is Legalized Land Tenure Necessary in Slum Upgrading? Learning from Rio's Land Tenure Policies in the Favela Bairro Program", Habitat International 34(1): $11-17$. 
HARVEY, David

2005 A Brief History of Neoliberalism. Oxford: Oxford University Press.

HITA, Maria Gabriela and John GLEDHILL

2010 "Antropologia na análise de situações periféricas urbanas", Cadernos Metrópole 12(23): 189-209.

HOLSTON, James

2009 "Dangerous Spaces of Citizenship: Gang Talk, Rights Talk and Rule of Law in Brazil”, Planning Theory 8(1): 12-31.

IBGE

2012 PNAD (Pesquisa Nacional por Amostra de Domicílios) 2011. Rio de Janeiro: Instituto Brasileiro de Geografia e Estadística.

INSTITUTO SANGARI

"Mapa da violência 2012: os novos padrões da violência homicida no Brasil", http://www. sangari.com/mapadaviolencia/, acceso, 21 de marzo, 2012.

IVO, Anete Brio Leal

2008 Viver por um fio: pobreza e política social. Sāo Paulo and Salvador: Annablume and $\mathrm{CRH} / \mathrm{UFBA}$.

LEBLON, Saul

2012 "O bangue-bangue paulista: a cidade quer saber", Carta Maior, http://www.cartamaior.com.br/templates/postMostrar.cfm?blog_id=6\&post_id=1130, acceso, 6 de Noviembre, 2012.

LINGER, Daniel Touro

1992 Dangerous Encounters: Meanings of Violence in a Brazilian City. Stanford: Stanford University Press.

MARTINS, Rodrigo

2012 “Seu país: crime não descansa”, Carta Capital, 14 November 2012.

MISSE, Michel

1997 “As ligações perigosas: mercado informal ilegal, narcotráfico e violência no Rio", Contemporaneidade \& Educação 2(1): 93-116.

NORONHA, Ceci Vilar

2008 "Criminalidad urbana y acciones de los escuadrones de la muerte en la Bahía (Brasil): de la impunidad a la pena máxima", Revista Latinoamericana de Seguridad Ciudadana 4 (FLACSO, Sede Ecuador, Quito): 103-110,

NUNES, Mónica and Jairnilson Silva PAIM

2005 "Um estudo etno-epidemiológico da violência urbana na cidade de Salvador, Bahía, Brasil: os atos de extermínio como objeto de analise", Caderno Saúde Publica, Rio de Janeiro 21(2): 459-468 
PATTERSON, Kent

2012 "The contradictions of the "new” Juárez", CIP-Americas Program, http://www. cipamericas.org/archives/8410, acceso, 27 de noviembre, 2012.

POCHMAN, Marcio

2009 “A volta da mobilidade social", http://www.ipea.gov.br/portal/index. php?option=com_content\&view=article\&id=521\&Itemid=2, acceso, 18 de octubre, 2011.

RIBEIRO DELGADO, Fernando, Raquel Elias DODGE y Sandra CARVALHO

2011 São Paulo sob achaque: corrupção, crime organizado e violência institucional em maio de 2006, http://global.org.br/programas/sao-paulo-sob-achaquecorrupcao-crime-organizado-e-violencia-institucional-em-maio-de-2006/, acceso, 18 de marzo, 2012.

ROLNIK, Raquel

2012 "Remoções forçadas em tempos do novo ciclo econômico", Carta Maior, http:// www.cartamaior.com.br/templates/materiaImprimir.cfm?materia_id=20790", acceso, 30 de agosto, 2012.

SEGURIDAD, JUSTICIA Y PAZ

2012 "San Pedro Sula (Honduras) la ciudad más violenta del mundo; Juárez, la segunda", http://www.seguridadjusticiaypaz.org.mx/sala-de-prensa/541-san-pedro-sula-laciudad-mas-violenta-del-mundo-juarez-la-segunda, acceso 21 de marzo, 2012.

SMITH, Neil

2002 "New globalism, new urbanism: gentrification as global urban strategy", Antipode, 34(3): 427-50.

SOARES, Luiz Eduardo

2006 “Segurança pública: presente e futuro", Estudos Avançados 20(56): 91-106.

SOARES, Sergei

2008 O ritmo de queda na desigualdade no Brasil é adequado? Evidências do contexto histórico e internacional. Texto para discussāo no. 1339. Brasilia: IPEA.

SOUZA, Jessé

2009 A ralé brasileira: quem é e como vive. Belo Horizonte: Editora UFMG.

STIGLITZ, Joseph E.

2012 The price of inequality. London: Allen Lane, Penguin Books.

TELLES, Vera da Silva

2010 A cidade nas fronteiras do legal e ilegal. Belo Horizonte: Argumentum.

UNDP

2011 Human Development Report 2011. Sustainability and Equity: A Better Future for All. Houndmills and New York: Palgrave Macmillan. 
UNITED NATIONS COMMISSIONER FOR HUMAN RIGHTS

2011 "Brazil off-course for World Cup and Olympics - UN housing expert", http://www. ohchr.org/EN/NewsEvents/Pages/DisplayNews.aspx?NewsID=10960, acceso, 28 de marzo, 2011.

WACQUANT, Loïc

2007 "Territorial stigmatization in the age of advanced marginality". Thesis Eleven 91: 66-77.

ZALUAR, Alba and Isabel Siqueira CONCEIÇÃO

2007 "Favelas sob o controle das milícias no Rio de Janeiro", São Paulo em Perspectiva 21(2): 89-101. 